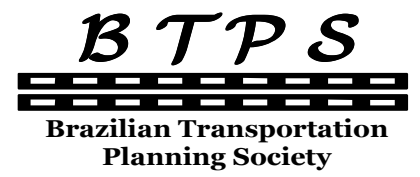

Journal of Transport Literature

Vol. 7, n. 3, pp. 137-176, Jul. 2013

Research Directory

\title{
Estudo de viabilidade de implantação de um novo corredor urbano na região do Igarapé da Lavanderia por meio de dinâmica de sistemas
}

\author{
[Feasibility study for establishment of a new urban corridor in the region of the \\ Igarapé da Lavanderia through dynamic systems] \\ Vittorio Figliuolo Neto*, Maria Ivanilde de Oliveira, \\ Jussara Socorro Cury Maciel \\ Universidade do Estado do Amazonas (UEA), Brazil, Universidade do Estado do Amazonas (UEA), Brazil, \\ Instituto Federal do Amazonas (IFAM), Brazil
}

Submitted 27 Mar 2012; received in revised form 10 Jul 2012; accepted 11 Jul 2012

\begin{abstract}
Resumo
A presente pesquisa visa analisar a viabilidade de implantação de um corredor viário urbano que interliga as zonas Norte e Leste ao Centro da cidade de Manaus através do Igarapé da Lavanderia, no bairro Petrópolis, localizado na zona sul da cidade. Para tal, foi realizada simulação de sistema dinâmico através do programa Vensim PLE para determinação da viabilidade de implantação. Para o sistema foram utilizados dois modelos, o modelo ideal, que deveria ser implementado, e o real, que em comparação a outros projetos viários recentemente executados na cidade. No primeiro caso, como esperado, concluiu-se que é viável construir o corredor. Já no segundo, devido a características como não conformidade de conforto e segurança, inexistência de outros itens de mobilidade (rampas de acesso e passarelas), congestionamentos nas vias de acesso, custos com manutenções não programadas e má conservação da via, concluiu-se, após a alimentação do sistema com os coeficientes previamente definidos, que caso não sejam revistos os conceitos e a importância de acessibilidade e mobilidade por parte dos gestores de trânsito e transporte, não será tecnicamente viável a implantação deste projeto.
\end{abstract}

Palavras-Chave: acessibilidade, mobilidade, sistemas dinâmicos, corredor urbano, viabilidade.

\begin{abstract}
This research aims to examine the feasibility of implementing a corridor that connects the urban areas North and East to the city Center of Manaus through the Igarapé da Lavanderia, Petrópolis neighborhood, located in the south of the city. To this end, was done a dynamic system through implementation of the program Vensim PLE to determine the feasibility of deployment. For the system we used two models, the ideal model, which should be implemented, and the real ones, which make a comparison to other road projects recently executed in the city. In the first case, as expected, it was found that it is possible to deploy the corridor. In the second, due to features such as non-compliant comfort and security flaws or no other items of mobility (access ramps and walkways), congestion on access routes, costs due to unscheduled maintenance and poor preservation of the route, it was concluded, after feeding the system with the coefficients previously defined, that if not reviewed the concepts and the importance of accessibility and mobility of managers of transit and transportation, will be not technically feasible the implementation of this project.
\end{abstract}

Key words: accessibility, mobility, dynamical systems, urban corridor, feasibility.

*Email: Vittorio.neto@hotmail.com.

\section{Recommended Citation}

Figliuolo Neto, V., Oliveira, M. I. and Maciel, J. S. C. (2013) Estudo de viabilidade de implantação de um novo corredor urbano na região do Igarapé da Lavanderia por meio de dinâmica de sistemas. Journal of Transport Literature, vol. 7, n. 3, pp. 137-176.

- JTL/RELIT is a fully electronic, peer-reviewed, open access, international journal focused on emerging transport markets and published by BPTS - Brazilian Transport Planning Society. Website www.transport-literature.org. ISSN 2238-1031.

This paper is downloadable at www.transport-literature.org/open-access. 


\section{Introdução}

As maiores cidades do Brasil sofrem com problemas de congestionamentos de carros em suas principais vias. Em Manaus não é diferente, uma vez que as principais vias, nas horas de maior movimento, apresentam filas de carros parados.

Capital do estado do Amazonas e componente da Região Metropolitana juntamente com as cidades de Presidente Figueiredo, Rio Preto da Eva, Careiro da Várzea, Novo Airão, Manacapuru, Iranduba e Itacoatiara, Manaus apresenta uma população de 1.802.014 habitantes e uma área de 11.401 quilômetros quadrados, conforme o Instituto Brasileiro de Geografia e Estatística IBGE (2010). Já sua economia é voltada para a indústria e serviços em geral.

Mesmo com o crescimento da cidade, principalmente nas zonas norte e leste, o fluxo de pessoas para o centro continua intenso, dado a concentração de uma grande quantidade de lojas, escolas e serviços nesta região. Desta forma, os corredores viários encontram-se em vias de saturação, agravados pela falta de novas ligações com o centro, o que dificulta sobremaneira os deslocamentos das pessoas que dependem de transporte coletivo, e que tem seus tempos de viagem cada vez mais ampliados.

A principal região de ligação entre a zona Leste e parte da Norte, ainda em franco crescimento, e o Centro da cidade são os bairros de Aleixo, Cachoeirinha, Petrópolis e São Francisco, localizados na zona Sul. Os corredores viários que ligam essas localidades se encontram saturados, inviabilizando a locomoção entre os dois pontos da cidade.

Tal problemática, muitas vezes, é tratada de maneira superficial e temporária, como, principalmente, construção de complexos viários ou novas vias com o intuito de suprir as necessidades do momento. Com isso, em um curto espaço de tempo com as mesmas características e uma maior dificuldade de se encontrar uma solução definitiva.

Partindo da possibilidade de implantação de uma ligação viária entre a Av. André Araújo e a Av. Codajás, este estudo objetivou analisar a viabilidade de implantação de um novo corredor viário urbano na região conhecida como Igarapé da Lavanderia, situada no bairro Petrópolis, 
utilizando como parâmetro os requisitos mínimos ideais exigidos pelos órgãos reguladores e financiadores de trânsito mundiais, a fim de se ter uma solução eficiente e duradoura para tal problema.

A análise de viabilidade se deu através da Dinâmica de Sistemas, método esse que possibilita a interação entre os indicadores de análise previamente determinados, fazendo com que o arranjo final de análise possa ficar o mais próximo possível da realidade a fim de se ter uma análise mais precisa do fator estudado. Este sistema de análises consiste na criação de simulações de condições a partir de indicadores predefinidos com um alto grau de relevância ao estudo pretendido. Após a definição de coeficientes e análise dos dados obtidos, o sistema estudado retornou que é inviável a construção do novo corredor conforme será visto a seguir.

O presente trabalho está assim dividido: Na seção 1, tem-se a conceituação de acessibilidade e mobilidade, além da ligação entre ambos. Na seção 2 tem se um breve histórico e definições de dinâmica de sistemas. Já a seção 3 apresenta a caracterização da área estudada. A seção 4 apresenta a metodologia utilizada. A seção 5 mostra a análise dos dados obtidos. Por fim, a conclusão mostra os resultados encontrados e os respectivos responsáveis por eles.

\section{Acessibilidade e mobilidade}

Este capítulo tem o intuito de apresentar uma breve conceituação de Acessibilidade e Mobilidade. Além disso, o mesmo apresenta a relação existente entre os dois conceitos.

\subsection{Acessibilidade}

O conceito de acessibilidade, de acordo com Raia Jr (2000), não é de fácil definição devido às variantes não ambíguas e quantificáveis. No entanto, suas definições são geralmente fundamentadas juntamente com os indicadores de acessibilidade a partir de diversas teorias.

Por sua vez, Lindemann (1998) afirma que tal conceito está relacionado às facilidades e dificuldades de chegada ou saída de um determinado lugar, numa área previamente delimitada. 
Com isso, Sales Filho (1996) apud Cunha et al (2004) define acessibilidade como sendo uma medida de distribuição espacial das atividades em relação a um ponto, ajustadas à habilidade e desejo das pessoas ou firmas que tem como objetivo comum superar a separação espacial.

Já Raia Jr (2000), diz que um entendimento para este tema é defini-lo como as características de dado local com relação à superação de obstáculos especiais.

Segundo Cunha et al (2004) o conceito de acessibilidade é a característica da área com relação à superação de uma fonte de fricção que se verifica espacialmente, seja essa fonte o tempo ou o espaço. Para o autor essas fontes de fricção levam em consideração as características do sistema de transporte, a atratividade de cada área e o custo percebido para realização da viagem, podendo este ser um fator determinante na distribuição de atividades numa dada área.

Com a união de todos esses conceitos, Raia Jr et al (1997) apud Cunha et al (2004) completa que acessibilidade torna possível o acesso dos indivíduos aos locais de emprego, lazer, estudos, equipamentos públicos (como praças) etc., e é função tanto do uso do solo quanto das características do sistema de transporte.

A partir desses conceitos se tem que o princípio de acessibilidade deve ser considerado na elaboração e construção de um corredor viário urbano. O mesmo deve possuir facilidades na infraestrutura física utilizada para o deslocamento da população entre as zonas da cidade, além de vias que possibilitem uma e rápida movimentação para seus usuários. Os itens mínimos a serem previsto e exigidos são, de forma geral: calçadas para deslocamento de pedestres, passarelas para uma travessia segura da população, sem que se tenha impactos ao fluxo dos carros e vias que atendam as exigências do tráfego nas horas de pico sem o surgimento de engarrafamentos.

\subsection{Mobilidade}

Mobilidade é conceituada, conforme Raia Jr (2000), como a relação entre os deslocamentos diários, viagens realizadas pela população de pessoas no espaço urbano ou no espaço pesquisado.

Outra interpretação para o conceito de mobilidade, usualmente utilizado, é o proposto por Tagore e Sikdar (1995), e também apresentado por Raia Jr (2000), que diz: “Capacidade dos 
indivíduos se moverem de um lugar para outro, depende da performance do sistema de transportes e características do indivíduo".

De acordo com Souza (1990) apud Carvalho e Silva, a mobilidade depende da acessibilidade e da necessidade de utilização de um meio de transporte. Enquanto Tyler (1997) apud Carvalho e Silva afirma que a mobilidade depende diretamente da acessibilidade e dos movimentos. Carvalho e Silva ainda complementam que para que a mobilidade exista é de extrema importância a existência da acessibilidade na região.

Portanto, tem-se que a mobilidade é a facilidade que se tem de acessar algum local. Para tanto, um corredor urbano, necessita fornecer ao seu usuário uma maior segurança nos seus deslocamentos, formas alternativas de locomoção, como ciclovias e linhas de trem, além da possibilidade de integração intermodal e rampas de acesso para portadores de necessidades especiais, por exemplo.

\subsection{Relação entre acessibilidade e mobilidade}

Acessibilidade e mobilidade têm seus conceitos intimamente interligados, uma vez que para se ter uma mobilidade de nível satisfatório necessita-se de um grande nível de acessibilidade. Para Tyler (1997), conforme mostra Carvalho e Silva, a relação que liga a mobilidade e acessibilidade se dá através da relação:

$$
\text { MOBILIDADE = ACESSIBILIDADE + MOVIMENTO }
$$

Em ambas as situações percebe-se que a acessibilidade está ligada a um fator externo. Sem essa união pode existir a acessibilidade, porém a mobilidade fica comprometida e, em muitos e principais casos, ela deixa até mesmo de haver.

Com o passar dos anos o pensamento e o interesse dos profissionais da área de transporte tem mudado de forma significativa. Neste intuito, Raia Jr (2000) diz que esse fator ocorre devido ao aumento da consciência das relações entre mobilidade, acessibilidade e qualidade de vida da população de uma dada área urbana.

Para evitar confusão entre os conceitos de ambos os assuntos Hanson (1995) apud Raia Jr (2000) fornece as seguintes definições sobre os temas: “Acessibilidade se refere ao número de 
oportunidades, também chamado de local de atividades, disponível dentro de certa distância ou tempo de viagem; mobilidade se refere à capacidade para se mover entre diferentes locais de atividades" (Hanson apud Raia Jr, 2000)

Portanto, para melhorar a acessibilidade de uma dada região sem alterar a mobilidade existente, é preciso fazer o planejamento de todo o uso do solo, principalmente utilizando-se o adensamento da região (Raia Jr, 2000). Assim, para que exista um grau de acessibilidade satisfatório deve-se ter uma demanda de mobilidade consistente e eficiente a fim de somente reorganizar o uso do solo e, com isso, mais facilmente melhorar o sistema de transporte de uma dada região.

\section{Dinâmica de sistemas}

Este capítulo apresenta o histórico da Dinâmica de Sistemas, seus principais conceitos e uma breve análise dos softwares que podem ser utilizados para a implementação deste sistema.

\subsection{Histórico}

De acordo com Leal Neto (2000) a dinâmica de sistemas vem se desenvolvendo há mais de 40 anos e foi concebida por Jay Wright Forrester, enquanto professor da Sloan School of Management (Escola de Administração Sloan), escola ligada ao Massachussetts Institute of Technology (MIT - Instituto de Tecnologia de Massachussets), no ano de 1956.

A concepção inicial desse sistema partiu do princípio de controle de retroalimentação, conceito esse usado na pesquisa eletromecânica desenvolvida pelo criador do sistema na época (Leal Neto, 2000).

Inicialmente foi usado o compilador SIMPLE (sigla em inglês que significa Simulation of Industrial Managemente Problems with Lots of Equations), e só anos depois foi desenvolvida uma linguagem própria para a análise de Sistemas Dinâmicos, o DYNAMO (Leal Neto, 2000). No Brasil, uma das principais aplicações desse segundo compilador foi a modelagem do sistema referente ao estudo MOBRAL - Movimento Brasileiro de Alfabetização, estudo de dissertação de mestrado (Oliveira, 1976 apud Leal Neto, 2000). 


\subsection{Conceitos}

Apesar de a idealização e criação da dinâmica de sistemas terem se desenvolvidos no ano de 1956, foi apenas em 1961, através de Forrester, que a mesma foi conceituada. Ele definiu que o foco principal é a determinação da estrutura de um sistema, que por sua vez, determina seu comportamento ao longo do tempo (Cover, 1996 apud Wiazowski, 1999).

A complexidade do método e a falta de ferramentas computacionais eficientes limitaram o campo de uso desse tipo de sistema. Somente na década de 1990, com o desenvolvimento de novos instrumentos computacionais é que se começou a utilizar o Sistema Dinâmico de forma mais abrangente e eficiente, uma vez que se tornou mais fácil aplica-lo (AGROSOFT, 1999).

Santos (2006) aponta que os objetivos da construção de um modelo dinâmico são: i) entender como um sistema real trabalha; ii) conhecer os fatores que influenciam o comportamento deste sistema; iii) explorar o efeito de vários cenários e políticas no comportamento do sistema; iv) ter a capacidade de compartilhar com outros participantes os seus resultados.

Ele ainda classifica os modelos como mentais ou formais. A diferença entre eles é: os modelos mentais são as representações simplificadas de um sistema complexo idealizado pela mente humana, já os modelos formais se apresentam como modelos em que o pensamento encontra-se estruturado e são representados por modelos computacionais.

Pidd (1996) apud Santos (2006) mostra que um sistema pode ser visto e modelado de diferentes formas: "Podem existir vários modelos para o mesmo sistema, dependendo dos olhos de quem o analisa".

\subsection{Softwares utilizados para implementação computacional de um sistema dinâmico}

Existem vários softwares para a implementação de sistemas dinâmicos. De todos, os mais utilizados são o Dynamo, Stella, Powersim e Vensim, os quais são descritos abaixo.

\subsubsection{Dynamo}

Conforme Santos (2006), o Dynamo foi a primeira linguagem de simulação de sistemas dinâmicos. Essa ferramenta foi desenvolvida no Massachussets Institute of Technology 
(Instituto de Tecnologia de Massachussets - MIT) por Jack Pugh, e sua comercialização se deu no início da década de 1960.

Ainda de acordo com Santos (2006) esse software é compatível com a plataforma DOS/Windows. Isso porque a mesma nos fornece um ambiente de desenvolvimento por meio de equações para a construção dos modelos, sem uma interface gráfica dos diagramas de laços causais ou dos diagramas de fluxo do modelo criado.

Sua utilização se torna difícil visto que o mesmo só possui versões pagas e uma interface de difícil entendimento e complexo desenvolvimento do sistema a ser utilizado para o estudo.

\subsubsection{Vensim PLE}

Esse software foi desenvolvido em meados dos anos 80 para utilização em consultoria de projetos pela empresa Ventana Systems Inc, tendo a sua primeira versão comercializada a partir de 1992. (Santos, 2006).

Diferente do Dynamo, o Vensim fornece um ambiente gráfico integrado para o desenvolvimento e análise de modelos de Dinâmicas de Sistemas, operando tanto em plataformas Windows como Macintosh (Santos 2006). Algumas vantagens desse sistema são a interface amigável, agilidade em desenvolver modelos e a editá-los, e ao selecionar um objeto de construção de modelo, ele permanece ativo até que se cancele a seleção. Além disso, tal ferramenta possui versões de comercialização pagas e gratuitas, facilitando assim o acesso e obtenção da mesma.

Visto a facilidade em criar sistemas e as vantagens acima apresentadas, o Vensim foi o modelador utilizado nesse trabalho.

\subsubsection{Stella}

Stella é um software comercializável, introduzido no mercado no ano de 1984 somente para plataformas Macintosh. Com o crescimento das plataformas Windows, e visando conquistar mais esse mercado, a empresa Isee Systems também desenvolveu uma versão para a mesma (Santos 2006). 
A seguir temos um resumo das principais características do Stella mostradas por Santos (2006): i) possui ambiente gráfico para o desenvolvimento dos modelos de fácil entendimento; ii) os modelos são desenhados por meio de uma série de ferramentas disponíveis em um menu de opções; iii) as equações são elaboradas através de caixas de diálogo.

\subsubsection{Powersim Studio 2005}

Por último tem-se o programa Powersim Studio, que foi desenvolvido em meados dos anos 80, através de um incentivo do governo norueguês com o intuito de aprimorar a qualidade de ensino nas escolas de Ensino Médio através de Dinâmica de Sistemas (Santos 2006).

Primeiramente desenvolveu-se o Mosaic, usado inicialmente para o desenvolvimento de jogos voltados para a educação. Ainda de acordo com o autor, o Powersim foi desenvolvido para ser utilizado em plataformas Windows, a partir da experiência do Mosaic, a fim de divulgar jogos interativos e ambientes baseados em simulação.

De acordo com Santos (2006), as principais características do Powersim são: i) construção dos modelos e definição das variáveis similar ao utilizado no Stella; ii) impossibilidade de ter representações de estudos de sensibilidade num mesmo gráfico; iii) só opera em plataforma Windows.

\section{Caracterização da área em estudo: Bairro de Petrópolis}

De acordo com o exposto no Jornal do Commercio apud Portal Amazônia, o bairro do Petrópolis foi fundado no dia 24 de setembro de 1951 pelo Coronel Alexandre Montoril, principal personagem do povoamento da região. Seu nome é oriundo da geografia do local, constituído de elevações e baixadas, igual à cidade de Petrópolis, no estado do Rio de Janeiro. Apesar de ter sido iniciado no ano de 1951, foi apenas no ano de 1953 que o processo de urbanização do local foi impulsionado, devido à grande enchente do Rio Amazonas. Segundo a Prefeitura de Manaus o bairro de Petrópolis se encontra situado na zona Sul da cidade de Manaus. 
No ano de 2006, de acordo com pesquisa realizada pelo CEFTRU (Centro de Formação de Recursos Humanos em Transporte), o bairro de Petrópolis possuía uma população de 41.748 habitantes e uma quantidade de casas igual a 9.711. Hoje essa população é estimada em aproximadamente 46 mil habitantes, conforme o Jornal do Commercio apud portal Amazônia.

O bairro possui uma extensão aproximada de 196.000 hectares, conforme o Jornal do Commercio apud portal Amazônia e limita-se com os bairros São Francisco, Cachoeirinha, Aleixo, Raiz e Coroado.

Ainda de acordo com o Jornal do Commercio, a comunidade usufrui de várias atividades comerciais, como padarias, loterias, farmácias, mercadinhos, sorveterias, lojas de eletrodomésticos, construção civil e outros. Entretanto, as variedades desses tipos de estabelecimentos comerciais geram poucas oportunidades de emprego, por serem, em sua maioria, familiares e de pequeno porte.

$\mathrm{Na}$ área onde foi realizado o estudo deste trabalho não é diferente. O igarapé da Lavanderia consiste em um igarapé com aproximadamente 1,34 km de extensão. A área escolhida para estudo se inicia na Avenida Paulo VI e termina na Rua Coronel Ferreira de Araújo, principalmente na Rua Canumã.

Na rua Canumã não passa linhas de ônibus, porém nas vias adjacentes ao igarapé circulam 06 linhas, segundo dados da Prefeitura Municipal de Manaus (2010). Além dessas, os moradores podem utilizar as linhas que passam pelas ruas próximas, nesse caso, 24 possibilidades, sendo que a maioria atravessa a Avenida André Araújo, distante algumas centenas de metros da Rua Canumã, onde se localiza o Igarapé. No total, a oferta de linhas para os moradores da região é de $12,77 \%$ do total de linhas da cidade de Manaus. 


\section{Metodologia}

Para a análise de viabilidade de implantação do corredor urbano foi escolhido utilizar a Dinâmica de Sistemas, pois com a mesma se pode realizar a ação entre os indicadores previamente determinados. Além disso, o arranjo final do modelo matemático fica mais próximo da realidade.

Para a aplicação desta metodologia adotou-se o procedimento de separar etapas de elaboração. Sendo a primeira a definição dos indicadores e subindicadores a serem trabalhados. Depois foram atribuídos pesos a esses fatores a partir de análises feitas em cada um deles. Em seguida, partiu-se para a elaboração do mapa dinâmico com os indicadores selecionados e os pesos atribuídos, para assim, montar o modelo matemático para proceder à simulação e a aplicação da fórmula, analisando a viabilidade de implantação da via. Tais fases estão apresentadas no organograma da Figura 1.

Para cada indicador, selecionado na primeira fase, foi atribuído um peso de acordo com as suas características, a fim de se criar o modelo matemático de análise dinâmica. Esses pesos variam de acordo com o indicador, conforme será apresentado no decorrer deste capítulo, assim como os possíveis valores para cada indicador.

Como parâmetro de comparação para a determinação de viabilidade, foram consideradas duas simulações diferentes, tendo em vista o projeto ideal e o projeto real. O projeto ideal leva em consideração as exigências e recomendações encontradas na literatura referente ao assunto e serve de validação do sistema criado, uma vez que é viável a criação de um corredor nestes parâmetros. Já o projeto real, ou executável, é a análise dos itens considerados ideais à viabilidade de implantação de uma via analisados a partir das últimas obras viárias realizadas na cidade de Manaus. As construções utilizadas como referência para análise deste estudo foram os complexos viários Antônio Simões e Gilberto Mestrinho e a Avenida Governador José Lindoso, todos construídos nos últimos 5 (cinco) anos e próximos à área em estudo. 


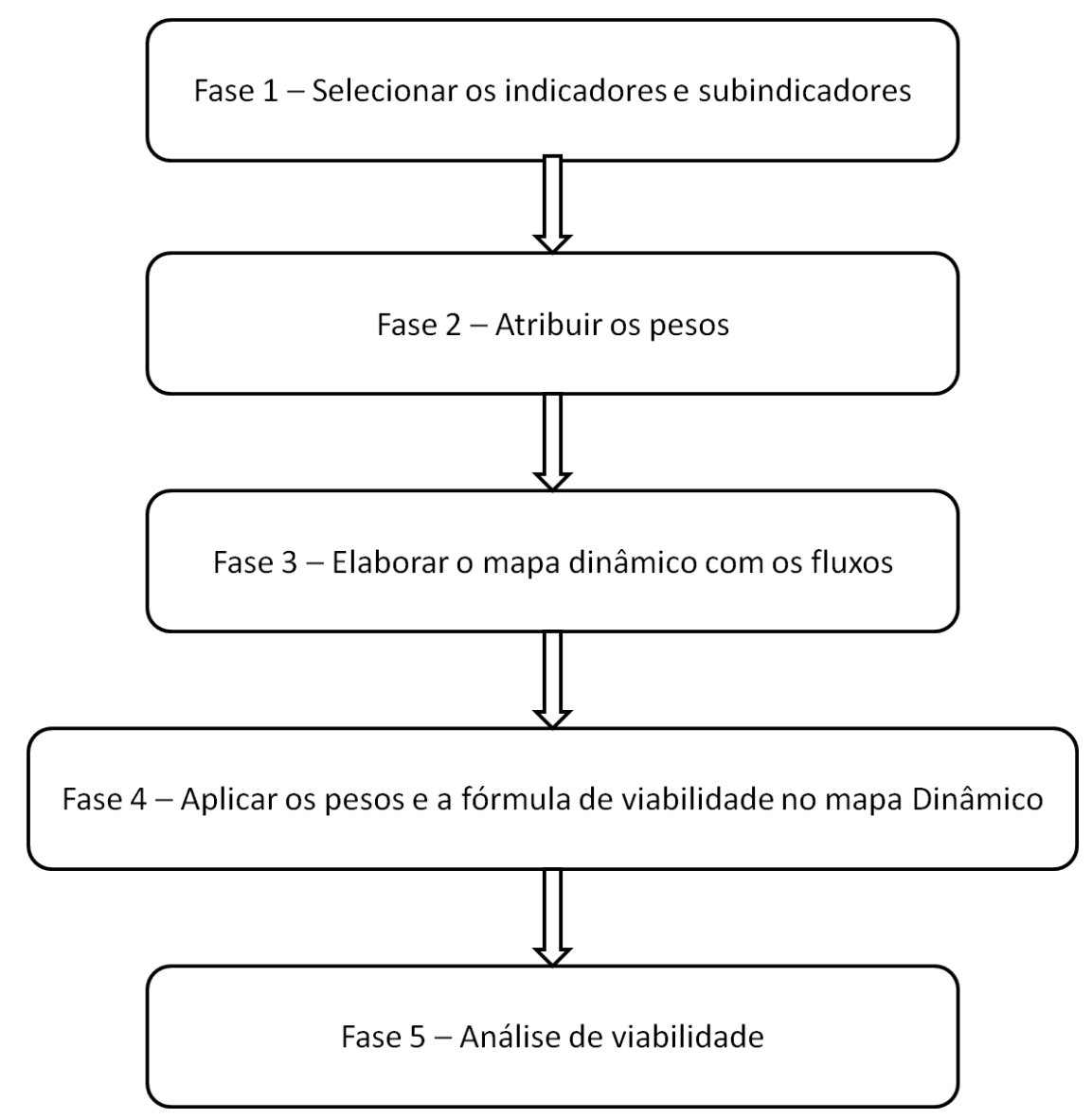

Figura 1 - Fases de execução para elaboração do mapa dinâmico ${ }^{1}$

Para a realização da análise, conforme indica a fase 3, foi elaborado o mapa dinâmico para o caso estudado. Neste mapa foram acrescentados todos os indicadores e seus respectivos subindicadores. Em alguns casos os subtópicos são interligados com dois itens distintos, como o que ocorre, por exemplo, com o subitem passarelas, que está ligado aos tópicos acessibilidade e mobilidade. O mesmo ocorre também com o item Contenção de Talude, que é interligado aos indicadores Custos e Ambiente. O mapa completo é apresentado na Figura 2.

Os indicadores adotados para a análise de viabilidade de implantação de um novo corredor urbano na implementação do sistema dinâmico são os descritos nos subtópicos 4.1 a 4.7. 


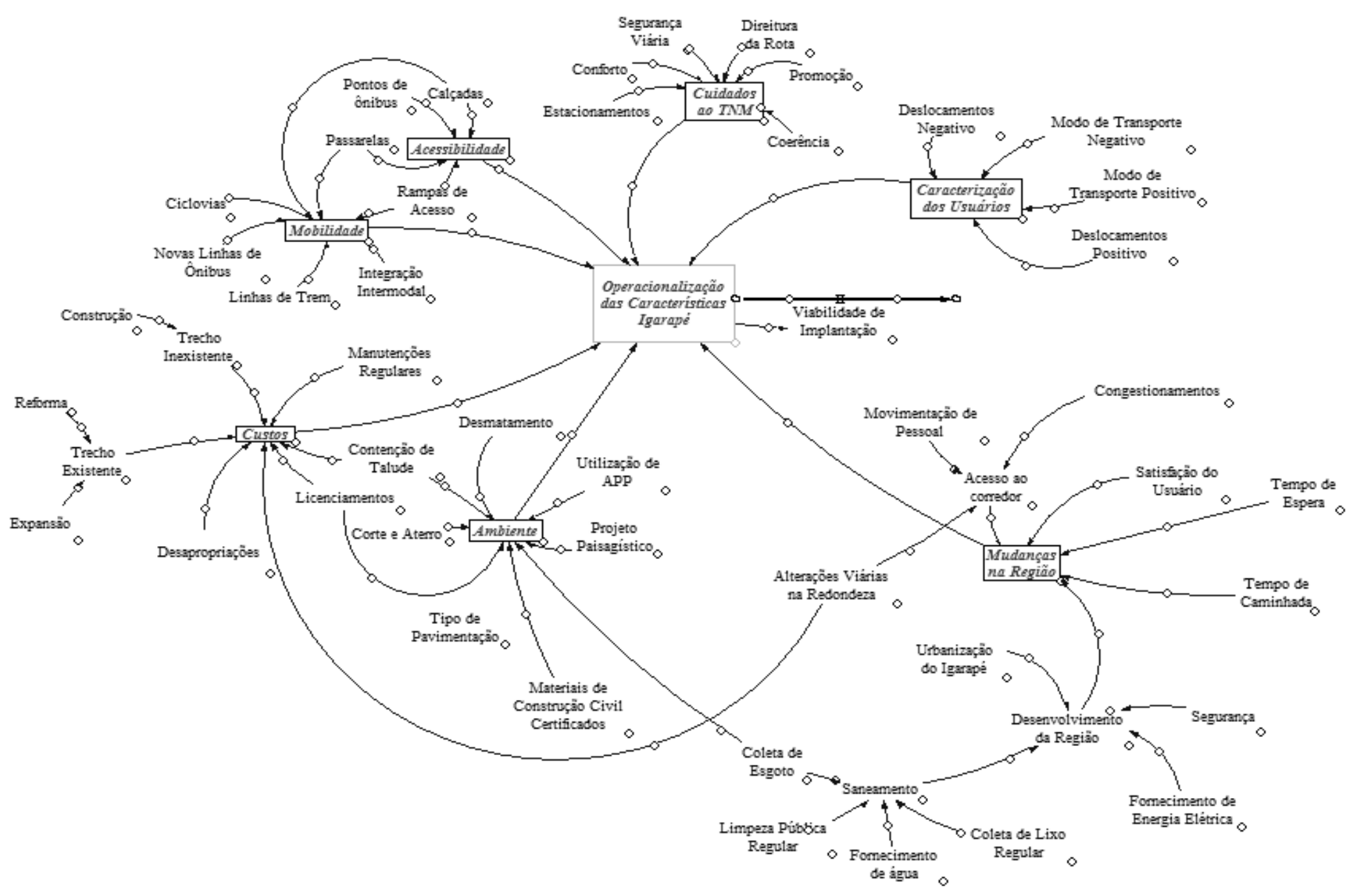

Figura 2 - Mapa de análise de viabilidade completo ${ }^{2}$ 


\subsection{Acessibilidade}

Conforme conceituado anteriormente, acessibilidade é o ato de um indivíduo acessar de forma rápida e eficiente seus destinos. A Associação Nacional de Transporte Público (ANTP) através da série Cadernos Técnicos (2007) e o Banco Mundial, através da edição Cidades em Movimento (2003), definem que os principais itens de acessibilidade a serem considerados em um projeto de uma nova via.

Na Tabela 1, tem-se os subindicadores definidos para a Acessibilidade e os pesos que podem ser atribuídos a cada um deles e seus motivos. Logo em seguida, tem-se os pesos adotados para cada indicador a partir da análise realizada na literatura.

Tabela 1 - Coeficientes a serem adotados para os itens Acessibilidade ${ }^{3}$

\begin{tabular}{|c|c|c|c|}
\hline Indicador & Coeficiente positivo & Coeficiente nulo & Coeficiente negativo \\
\hline Calçadas & $\begin{array}{c}1 \\
\text { Existe conforme } \\
\text { recomendado }\end{array}$ & $\begin{array}{c}0 \\
\text { Existe desconforme o } \\
\text { recomendado }\end{array}$ & Não existe \\
\hline Passarelas & $\begin{array}{c}1 \\
\text { Existe conforme } \\
\text { recomendado }\end{array}$ & $\begin{array}{c}\text { Existe desconforme o } \\
\text { recomendado }\end{array}$ & Não existe \\
\hline Pontos de Ônibus & $\begin{array}{c}1 \\
\text { Existe conforme } \\
\text { recomendado }\end{array}$ & $\begin{array}{c}\text { Existe desconforme o } \\
\text { recomendado }\end{array}$ & Não existe \\
\hline $\begin{array}{c}\text { Rampas de Acesso } \\
\text { (Para calçadas e pontos } \\
\text { de ônibus elevados) }\end{array}$ & $\begin{array}{c}\text { Existe conforme } \\
\text { recomendado }\end{array}$ & $\begin{array}{c}\text { Existe desconforme o } \\
\text { recomendado }\end{array}$ & Não existe \\
\hline
\end{tabular}

i) Calçadas: adotar coeficiente 1, pois devem ser construídas calçadas de acordo com o que a acessibilidade exige, ou seja, calçada larga e segura aos pedestres;

ii) Passarelas: adotar coeficiente 1, pois devem ser construídas passarelas para a travessia de pessoas, na extensão do igarapé, sem que as mesmas sofram qualquer tipo de risco;

iii) Rampas de Acesso: adotar coeficiente 2, pois o projeto prevê acesso aos portadores de necessidades especiais às calçadas e pontos de ônibus através de rampas, a fim de suavizar e melhorar o seu acesso;

iv) Pontos de ônibus: adotar coeficiente 1, pois deverão existir locais para embarque e desembarque de passageiros; 
A Figura 3 apresenta as variáveis utilizadas na análise do indicador Acessibilidade aplicadas ao sistema dinâmico, conforme aparecem no modelo matemático de análise.

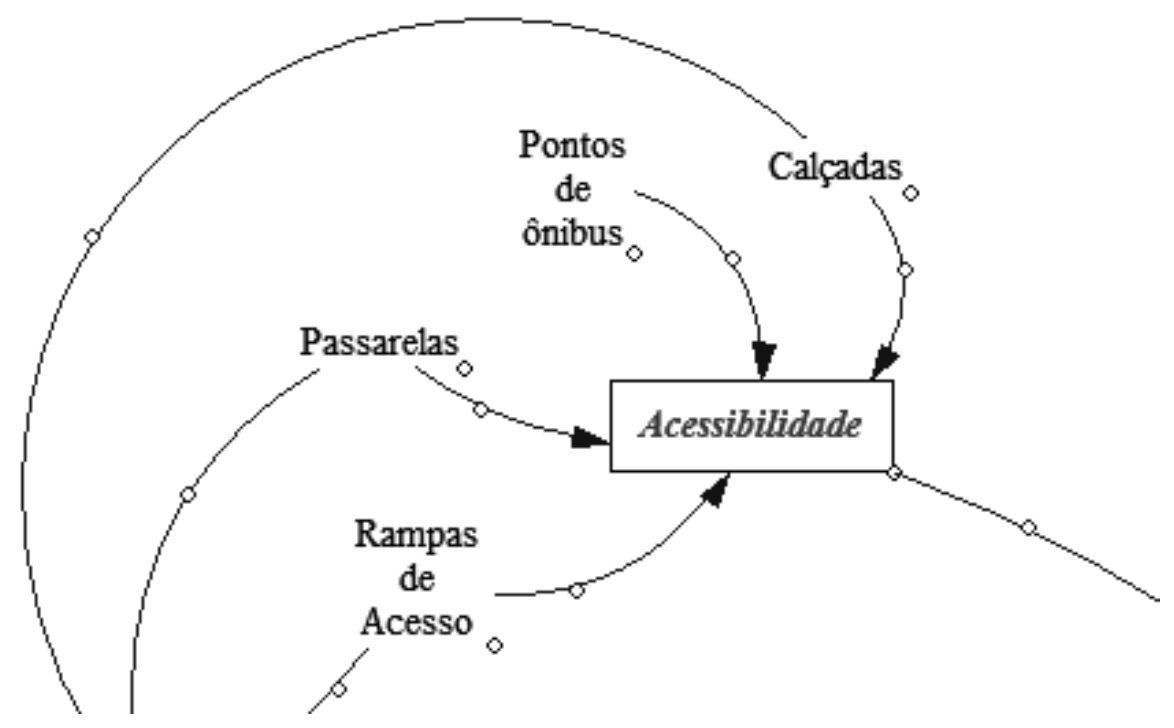

Figura 3 - Análise da acessibilidade ${ }^{4}$

\subsection{Mobilidade}

Mobilidade, definida como sendo a facilidade que um indivíduo tem de acessar um determinado local, teve como parâmetros de análise itens referentes a disponibilidade de transporte intermodal no novo corredor urbano, segurança e qualidade de vias e calçadas, conforme indicado na série de Cadernos Técnicos (2007) da ANTP.

Na Tabela 2, tem-se os subindicadores definidos para a Mobilidade dos usuários e os pesos que podem ser atribuídos a cada um deles e seus motivos. Logo em seguida, tem-se os pesos adotados para cada indicador a partir da análise realizada na literatura.

Tabela 2 - Coeficientes a serem adotados para os itens Mobilidade ${ }^{5}$

\begin{tabular}{|c|c|c|c|}
\hline Indicador & Coeficiente positivo & Coeficiente nulo & Coeficiente negativo \\
\hline Ciclovias & $\begin{array}{c}1 \\
\text { Existe conforme } \\
\text { recomendado }\end{array}$ & $\begin{array}{c}\text { Existe desconforme o } \\
\text { recomendado }\end{array}$ & Não existe \\
\hline Integração Intermodal & $\begin{array}{c}1 \\
\text { Existe conforme } \\
\text { recomendado }\end{array}$ & $\begin{array}{c}\text { Existe desconforme o } \\
\text { recomendado }\end{array}$ & -1 \\
\hline
\end{tabular}

${ }^{4}$ Fonte: Autores. 


\begin{tabular}{|c|c|c|c|}
\hline \multicolumn{4}{|c|}{ Continuação da Tabela 2 } \\
\hline Linhas de trem & $\begin{array}{c}1 \\
\text { Existe conforme } \\
\text { recomendado }\end{array}$ & $\begin{array}{c}\text { Existe desconforme o } \\
\text { recomendado }\end{array}$ & Não existe \\
\hline $\begin{array}{c}\text { Novas Linhas de } \\
\text { Onnibus }\end{array}$ & $\begin{array}{c}1 \\
\text { Existe conforme } \\
\text { recomendado }\end{array}$ & $\begin{array}{c}\text { Existe desconforme o } \\
\text { recomendado }\end{array}$ & -1 \\
Não existe \\
\hline
\end{tabular}

i) Ciclovias: adotar coeficiente 0, pois a cidade de Manaus não possui ciclovias e por isso não serão considerado neste projeto;

ii) Novas Linhas de ônibus: adotar coeficiente 1, pois deverão ser criada novas linhas de ônibus, a fim de atender a região do corredor de forma rápida e eficiente;

iii) Linhas de Trem: adotar coeficiente 0, pois na cidade de Manaus não existem linhas férreas;

iv) Integração Intermodal: adotar coeficiente 0, pois não é considerado ligação intermodal nas redondezas da via em Manaus;

A Figura 4 apresenta as variáveis utilizadas na análise do indicador Mobilidade aplicadas ao sistema dinâmico, conforme aparecem no modelo matemático de análise.

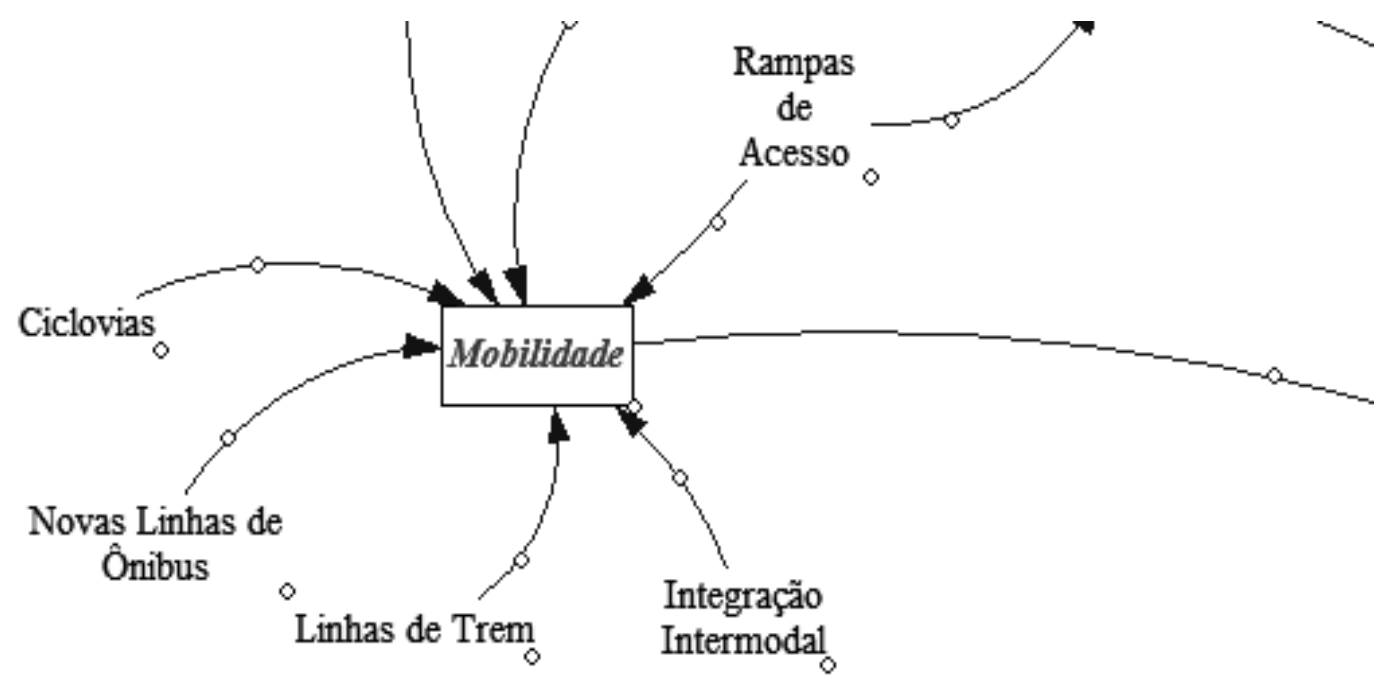

Figura 4 - Análise da mobilidade ${ }^{6}$ 


\subsection{Cuidados ao Transporte Não Motorizado (TNM)}

A implantação de um novo corredor viário exige mudanças na estruturação da região que receberá essa implantação. Para implantação de um corredor urbano deve-se levar em consideração a segurança da via, a direitura da rota (via possui traçado o mais retilíneo possível), conforto aos usuários e outros (Cadernos Técnicos, 2007). A seguir estão descritos estes e outros itens referentes a Cuidados ao TNM e seus respectivos coeficientes:

Na Tabela 3, tem-se os subindicadores definidos para o indicador Cuidados ao Transporte Não Motorizado e os pesos que podem ser atribuídos a cada um deles e seus motivos. Logo em seguida, tem-se os pesos adotados para cada indicador a partir da análise realizada na literatura.

Tabela 3 - Coeficientes a serem adotados para os itens Cuidados ao TNM $^{7}$

\begin{tabular}{|c|c|c|c|}
\hline Indicador & Coeficiente positivo & Coeficiente nulo & Coeficiente negativo \\
\hline Coerência & $\begin{array}{c}1 \\
\text { Existe conforme } \\
\text { recomendado }\end{array}$ & $\begin{array}{c}\text { Existe desconforme o } \\
\text { recomendado }\end{array}$ & $\begin{array}{c}-1 \\
\text { Não existe }\end{array}$ \\
\hline Conforto & $\begin{array}{c}1 \\
\text { Existe conforme } \\
\text { recomendado }\end{array}$ & $\begin{array}{c}\text { Existe desconforme o } \\
\text { recomendado }\end{array}$ & -1 \\
Direitura da Rota & $\begin{array}{c}1 \\
\text { Existe conforme } \\
\text { recomendado }\end{array}$ & $\begin{array}{c}\text { Existe desconforme o } \\
\text { recomendado }\end{array}$ & Não existe \\
\hline Estacionamentos & $\begin{array}{c}1 \\
\text { Existe conforme } \\
\text { recomendado }\end{array}$ & $\begin{array}{c}\text { Existe desconforme o } \\
\text { recomendado }\end{array}$ & Não existe \\
\hline Promoção & $\begin{array}{c}1 \\
\text { Existe conforme } \\
\text { recomendado }\end{array}$ & $\begin{array}{c}\text { Existe desconforme o } \\
\text { recomendado }\end{array}$ & -1 \\
\hline Segurança Viária & $\begin{array}{c}1 \\
\text { Existe conforme } \\
\text { recomendado }\end{array}$ & $\begin{array}{c}\text { Existe desconforme o } \\
\text { recomendado }\end{array}$ & Não existe \\
\hline
\end{tabular}

i) Segurança Viária: adotar coeficiente 1, pois será pensado em primeiro lugar na segurança dos usuários da via;

ii) Direitura da Rota: é oferecer rotas diretas, sem desvios e com o mínimo de interferência (postes, telefones públicos e outros) para os transportes não motorizados (TNM); 
iii) Coerência: conectar origens e destinos dos ciclistas e integrá-los à paisagem urbana. Adotar coeficiente 0 , pois não haverá ciclovia no novo corredor;

iv) Conforto: como o TNM depende única e exclusivamente do esforço físico do ser humano, deve-se tomar medidas a fim de proporcionar conforto aos usuários, tais como oferecer superfícies de rolamento regulares, impermeáveis e antideslizantes;

v) Estacionamentos: segurança na hora de estacionar e guardar a bicicleta na chegada ao destino de forma confiável e eficiente;

vi) Promoção: promover a utilização de bicicletas como transporte alternativo, verde, barato e eficiente para a população em geral, e em especial da região estudada;

A Figura 5 apresenta as variáveis utilizadas na análise do indicador Cuidados ao TNM aplicadas ao sistema dinâmico, conforme aparecem no modelo matemático de análise.

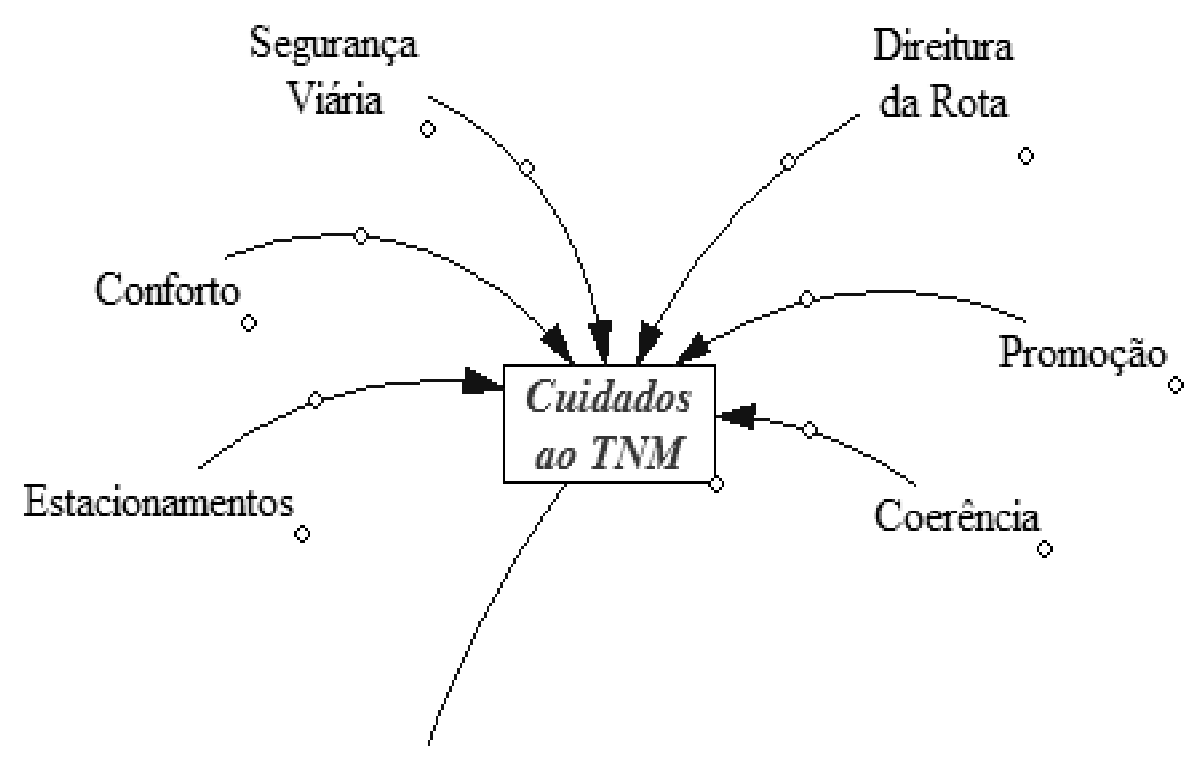

Figura 51 - Análise dos Cuidados ao Transporte Não Motorizado 8

\subsection{Custos}

Visa fazer um levantamento das condições dos custos de implantação e manutenção de um corredor viário. Esse item possui um impacto negativo à implantação do corredor. Os itens utilizados foram retirados da Série Cadernos Técnicos criado pelo ANTP (2007) e do produto técnico Cidades em Movimento do Banco Mundial (2003) e são: 
Na Tabela 4, tem-se os indicadores definidos para o Custos envolvendo a construção e manutenção de um novo corredor urbano, conforme literatura e os pesos que podem ser atribuídos a cada um deles e seus motivos. Logo em seguida, tem-se os pesos adotados para cada indicador a partir da análise realizada na literatura.

Tabela 4 - Coeficientes a serem adotados para os itens Custos9

\begin{tabular}{|c|c|c|c|}
\hline Indicador & Coeficiente positivo & Coeficiente nulo & Coeficiente negativo \\
\hline $\begin{array}{c}\text { Alterações Viárias na } \\
\text { Redondeza }\end{array}$ & $\begin{array}{c}0 \\
\text { Nenhuma alteração }\end{array}$ & Pouca alteração & $\begin{array}{c}-1 \\
\text { Muita alteração }\end{array}$ \\
\hline Contenção de Talude & 1 & 0 & -1 \\
Não necessário & Pouco necessário & Muito necessário \\
\hline Desapropriações & 1 & 0 & -1 \\
\hline $\begin{array}{c}\text { Licenciamentos } \\
\text { (Considerar três } \\
\text { licenciamentos } \\
\text { necessários) }\end{array}$ & $\begin{array}{c}\text { Sem burocracia para } \\
\text { obtenção }\end{array}$ & $\begin{array}{c}\text { Pouca burocracia para } \\
\text { obtenção }\end{array}$ & $\begin{array}{c}\text { Muita burocracia para } \\
\text { obtenção }\end{array}$ \\
\hline $\begin{array}{c}\text { Manutenções } \\
\text { Regulares (Considerar } \\
\text { Manutenções } \\
\text { Preventivas e } \\
\text { Corretivas) }\end{array}$ & 1 & 0 & -1 \\
\hline $\begin{array}{c}\text { Trecho existente } \\
\text { (Considerar Expansão } \\
\text { e Reforma) }\end{array}$ & Feitas regularmente & Feitas imediatamente & $\begin{array}{c}\text { Feitas } \\
\text { Emergencialmente }\end{array}$ \\
\hline $\begin{array}{c}\text { Trecho Inexistente } \\
\text { (Considerar } \\
\text { construção) }\end{array}$ & Nenhuma interferência & Pouca Interferência & Muita Interferência \\
\hline
\end{tabular}

i) Reforma e expansão do trecho existente: adotar coeficiente -2, -1 para reforma e -1 para expansão, pois a condição da via hoje é precária e necessita de reformas e reforço. Além disso, a mesma possui apenas uma faixa de tráfego, logo a necessidade de expansão de duas novas faixas;

ii) Construção de trecho viário inexistente: adotar coeficiente -1, pois a via existente hoje possui um comprimento de apenas 420 metros dos 1,34 quilômetros total. Por tanto, necessita-se a construção de novas vias;

iii) Desapropriação: adotar coeficiente -1, pois existirá um alto grau de desapropriação, devido ao fato de toda a extensão do igarapé já estar tomada por residências em suas proximidades; 
iv) Licenciamentos: adotar coeficiente -3, um para cada licença descrita a seguir, pois para qualquer tipo de construção é exigido que se obtenha as licenças de operação, instalação e ambiental na SEMMAS, não diferente para essa situação;

v) Manutenções regulares: adotar coeficiente -1, pois para que a obra possua uma vida útil maior, deverá ser realizada a conservação das mesmas através de manutenções preventivas (Banco Mundial, 2003);

vi) Contenção de Talude: adotar coeficiente -1 , pois as redondezas do igarapé possuem depressões e barrancos muito íngremes e elevados, necessitando de altos custos para a proteção da via;

Por fim, a Figura 6 apresenta os subindicadores definidos para o indicador custo e estão dispostas conforme se encontram no modelo matemático desenvolvido através de Dinâmica de Sistemas para a determinação da viabilidade de implantação de um novo corredor urbano.

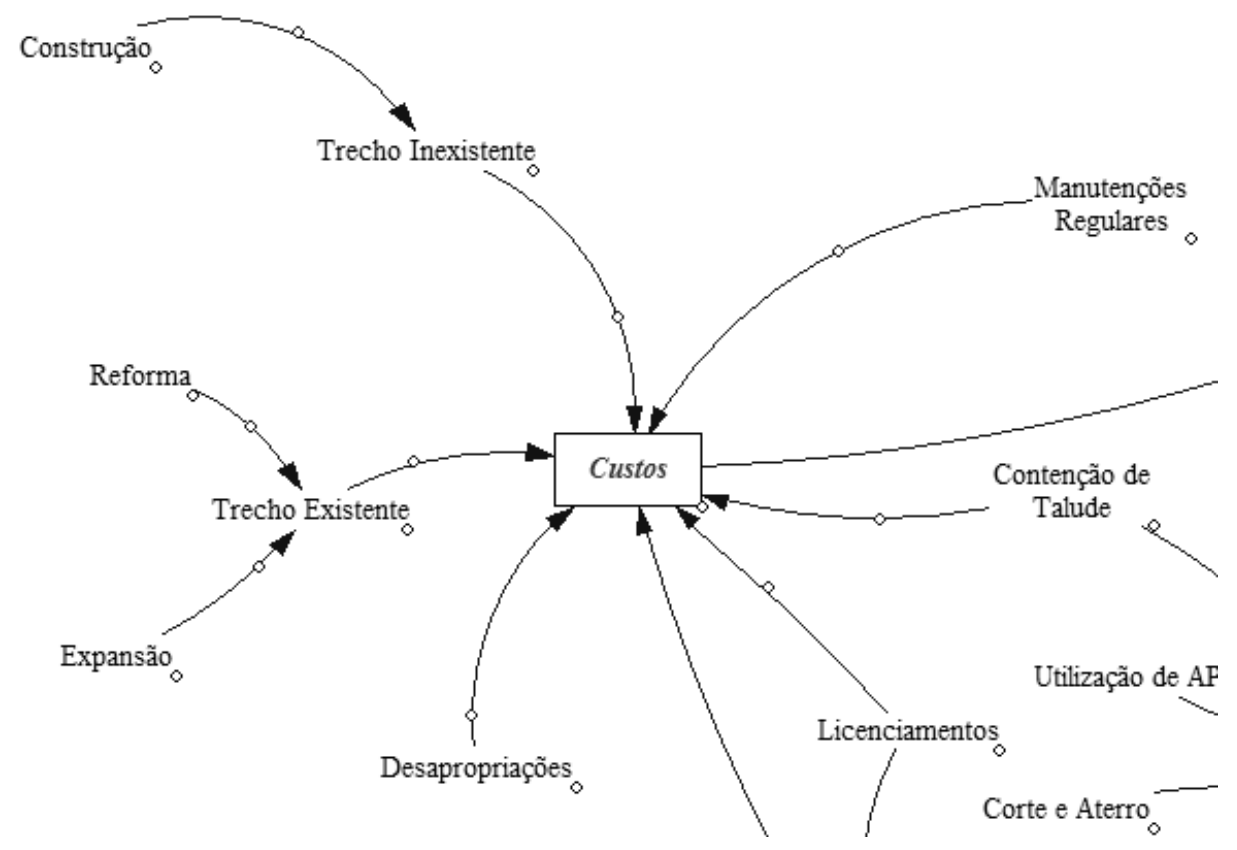

Figura 6 - Análise dos Custos ${ }^{10}$

\subsection{Ambiente}

Com o intuito de analisar os possíveis impactos ambientais que as obras e utilização do novo corredor podem gerar, foram utilizadas as considerações feitas pelos órgãos ambientais do 
município (SEMMAS) e da esfera estadual (IPAAM) definidos para uma maior preservação ambiental

$\mathrm{Na}$ Tabela 5, tem-se os subindicadores definidos para o Ambiente onde serão desenvolvidos os serviços de criação de um novo corredor e a preocupação do cuidado com o meio ambiente, conforme literatura e os pesos que podem ser atribuídos a cada um deles e seus motivos. Logo em seguida, tem-se os pesos adotados para cada indicador a partir da análise realizada na literatura.

Tabela 5 - Coeficientes a serem adotados para os itens Ambiente ${ }^{11}$

\begin{tabular}{|c|c|c|c|}
\hline Indicador & Coeficiente positivo & Coeficiente nulo & Coeficiente negativo \\
\hline \multirow{2}{*}{ Corte e Aterro } & 1 & 0 & -1 \\
& Nenhum Movimento & Pouco Movimento de & Muito Movimento de \\
Te Terra & 1 & 0 & -1 \\
\hline Desmatamento & Nenhum & Pouco & Muito \\
\hline Materiais de & 1 & 0 & -1 \\
Construção Civil & Fácil acesso e barato & Fácil acesso e caro & Difícil acesso \\
\hline Certificados & 1 & 0 & -1 \\
Projeto Paisagístico & Considerado toda a & Considerado & Não considerado \\
\hline Tipo de Pavimentação & Não impermeabiliza o & pontualmente & -1 \\
& solo & 0 & Impermeabiliza pouco \\
& 1 & 0 & Impermeabiliza o solo \\
\hline Utilização de APP & Não adentra & Adentra pouco & Adentra muito \\
\hline
\end{tabular}

i) Desmatamento: adotar coeficiente 0, pois não será realizado desmatamento;

ii) Utilização de Área de Proteção Permanente (APP) - faixa de 30 metros da margem dos igarapés: adotar coeficiente -1, pois o corredor está dentro dessa faixa de 30 metros;

iii) Alteração na topografia local com corte e aterro: adotar coeficiente -2 , usar -1 para o corte e -1 para o aterro, devido à característica acidentada do terreno em alguns trechos; 
iv) Tipo de pavimentação (possível impermeabilização do solo): Adotar coeficiente -1, pois a capa utilizada mudará as características de percolação da água no solo. A mesma servirá como um impermeabilizante para a via. Caso contrário adotar coeficiente 0 ;

v) Materiais de construção certificados: Adotar coeficiente 1, pois a exigência hoje por uso de materiais certificados e com procedência conhecida é de suma importância, principalmente para se retirar as licenças ambientais;

vi) Projeto Paisagístico: Adotar coeficiente 1, pois será concebido um projeto paisagístico na concepção da via, a fim de auxiliar nos itens de mobilidade. Caso contrário adotar coeficiente -1 ;

vii) Licenciamento: adotado no parâmetro custos e interligado ao parâmetro custo ambiente;

viii) Urbanização do Igarapé: adotado no parâmetro mudanças na região e interligado ao parâmetro custo;

ix) Coleta de Esgoto: adotado no parâmetro mudanças na região e interligado ao parâmetro custo.

A Figura 7 apresenta as variáveis utilizadas na análise do grupo Ambiente no sistema dinâmico.

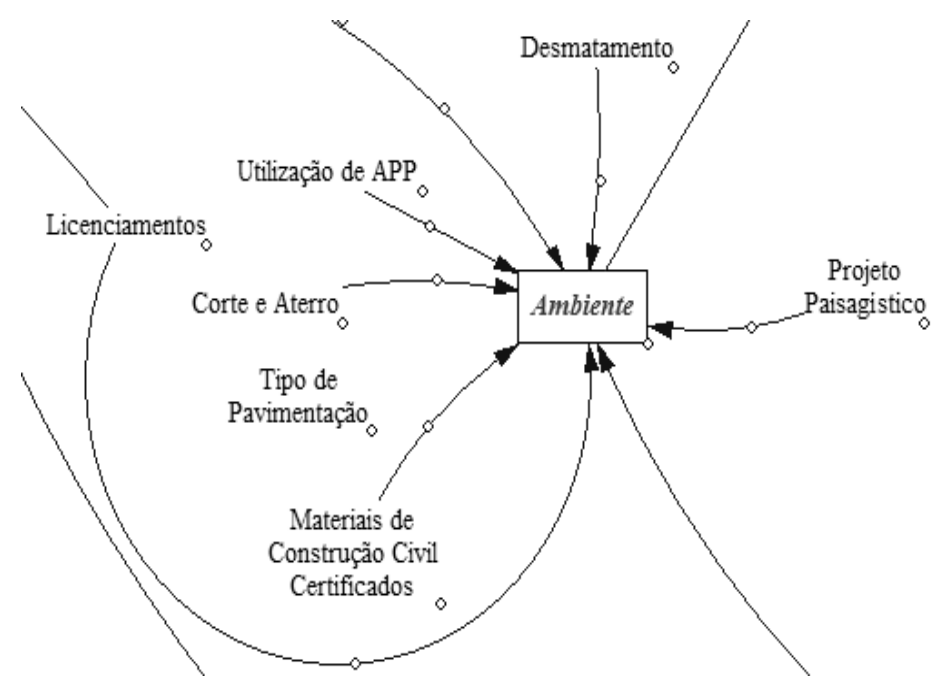

Figura 7 - Análise do Ambiente ${ }^{12}$ 


\subsection{Caracterização dos usuários}

Relaciona os benefícios que impactam diretamente na viabilidade de implementação, a partir do modo de locomoção e deslocamento atual dos usuários da região levantados a partir de uma pesquisa O/D aplicada em dois dias em 50\% da área estudada a fim de se determinar a caracterização dos usuários da região.

Na Tabela 6, tem-se os sudindicadores definidos para a Caracterização dos Usuários de transporte que vivem na região do Igarapé da Lavanderia, conforme pesos que podem ser atribuídos a cada um deles e seus motivos. Logo em seguida, tem-se a Tabela 7 com a divisão de pesos a partir dos quantitativos achados em campo. Para, por fim, apresentar os pesos adotados para cada indicador a partir da análise realizada na literatura.

Tabela 6 - Coeficientes a serem adotados para os itens Caracterização dos Usuários ${ }^{13}$

\begin{tabular}{|c|c|c|c|}
\hline Indicador & Coeficiente positivo & Coeficiente nulo & Coeficiente negativo \\
\hline $\begin{array}{l}\text { Deslocamentos } \\
\text { Positivos }\end{array}$ & $\begin{array}{c}05 \text { a } 01 \\
\text { Conforme tabela } 2\end{array}$ & $\begin{array}{c}0 \\
\text { Conforme tabela } 2\end{array}$ & $\begin{array}{c}-1 \text { a }-5 \\
\text { Conforme tabela } 2\end{array}$ \\
\hline $\begin{array}{l}\text { Deslocamentos } \\
\text { Negativos }\end{array}$ & $\begin{array}{c}05 \text { a } 01 \\
\text { Conforme tabela } 2\end{array}$ & $\begin{array}{c}0 \\
\text { Conforme tabela } 2\end{array}$ & $\begin{array}{c}-1 \text { a }-5 \\
\text { Conforme tabela } 2\end{array}$ \\
\hline $\begin{array}{l}\text { Meio de Transporte } \\
\text { positivo }\end{array}$ & $\begin{array}{c}05 \text { a } 01 \\
\text { Conforme tabela } 2\end{array}$ & $\begin{array}{c}0 \\
\text { Conforme tabela } 2\end{array}$ & $\begin{array}{c}-1 \text { a }-5 \\
\text { Conforme tabela } 2\end{array}$ \\
\hline $\begin{array}{l}\text { Meio de Transporte } \\
\text { negativo }\end{array}$ & $\begin{array}{c}05 \text { a } 01 \\
\text { Conforme tabela } 7\end{array}$ & $\begin{array}{c}0 \\
\text { Conforme tabela } 7 \\
\end{array}$ & $\begin{array}{c}-1 \text { a }-5 \\
\text { Conforme tabela } 7 \\
\end{array}$ \\
\hline
\end{tabular}

Tabela 7 - Coeficientes a serem adotados para os itens caracterização dos usuários ${ }^{14}$

\begin{tabular}{|c|c|}
\hline Intervalo & Coeficiente \\
\hline Até 50 & 0 \\
\hline De 51 a 150 & 1 \\
\hline De 151 a 300 & 2 \\
\hline De 301 a 450 & 3 \\
\hline De 451 a 600 & 4 \\
\hline Acima de 600 & 5 \\
\hline
\end{tabular}

i) Deslocamentos positivos: quantidade de deslocamentos realizados para as regiões que envolvam os bairros a serem interligados pela proposta de corredor urbano. Seu valor tem influencia positiva ao sistema. Envolve as macrounidades Centro, Integração e Leste definidas no Plano Diretor de Manaus (2006). Adotar coeficiente 5, pois o total de deslocamentos para as macrounidades que o corredor urbano atende é de 631 pessoas. Tal índice alto se dá ao fato da localização do novo corredor, se situando na zona Centro-Sul da cidade;

\footnotetext{
${ }^{13}$ Fonte: Autores. 
ii) Deslocamentos negativos: quantidade de deslocamentos realizados para áreas opostas às de implantação do sistema. Seu valor tem influencia negativa ao sistema dinâmico. Envolve as macrounidades Orla do Rio Negro Oeste, Orla do Rio Negro Leste, Tarumã-Açu e Ducke definidas pelo Plano Diretor de Manaus (2006). Adotar coeficiente 0 , pois o total de deslocamentos para as macrounidades que o corredor urbano atende é de 32 pessoas;

iii) Meio de Transporte positivo: meio de transportes que poderão usufruir do novo corredor urbano. Seu valor final tem influencia positiva ao sistema. Envolve os meios de transporte ônibus, microônibus, automóvel e moto. Adotar coeficiente 3, pois o total de meios de transporte utilizados para deslocamentos é de 399;

iv) Meio de Transporte negativo: meio de transportes que não poderão usufruir do novo corredor urbano. Seu valor final tem influencia negativa ao sistema. Envolve os meios de transporte táxi, bicicleta, a pé, veículo fretado, moto táxi. Adotar coeficiente 2, pois o total de meios de transporte utilizados para deslocamentos é de 264;

A Figura 8 a seguir apresenta as variáveis utilizadas na análise do grupo Caracterização dos Usuários no sistema dinâmico.

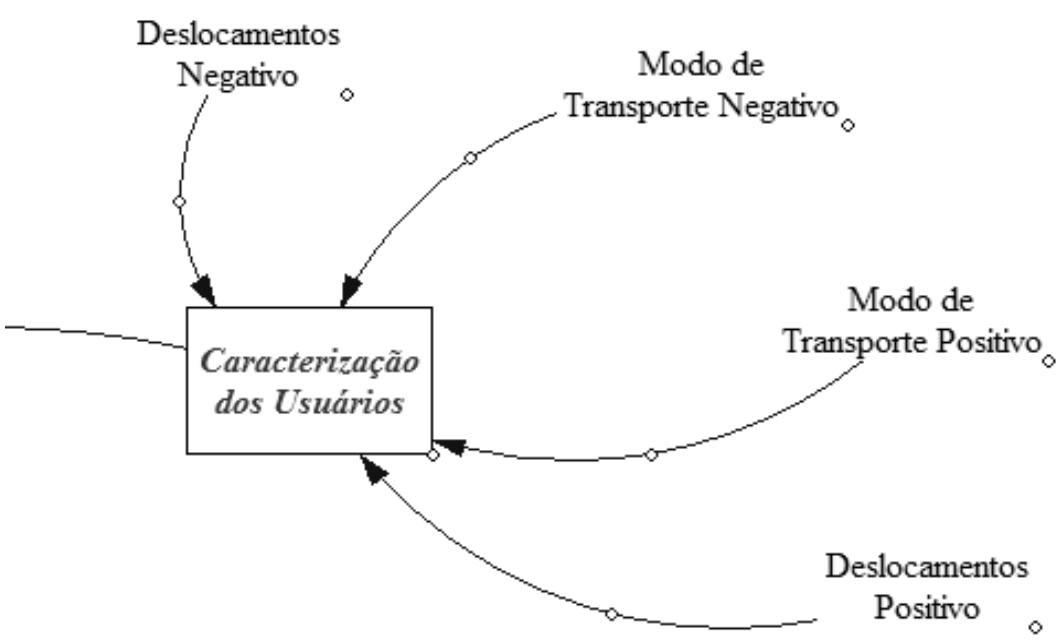

Figura 8 - Análise da caracterização dos usuários ${ }^{15}$ 


\subsection{Mudanças na região}

Relaciona as melhorias a serem feitas em benefício da população residente na região. Seu fator tem, na maior parte dos casos, relevância positiva à implementação do sistema.

$\mathrm{Na}$ Tabela 8, tem-se os subindicadores definidos para o Mudanças na Região conforme literatura e os pesos que podem ser atribuídos a cada um deles e seus motivos. Logo em seguida, tem-se os pesos adotados para cada indicador a partir da análise realizada na literatura.

Tabela 8 - Coeficientes a serem adotados para os itens Mudanças na Região ${ }^{16}$

\begin{tabular}{|c|c|c|c|}
\hline Indicador & Coeficiente positivo & Coeficiente nulo & Coeficiente negativo \\
\hline $\begin{array}{l}\text { Acesso ao Corredor } \\
\text { (Considerar as } \\
\text { Alterações Viárias } \\
\text { Necessárias, } \\
\text { Congestionamento e } \\
\text { Necessidade de } \\
\text { Agentes de Trânsito } \\
\text { nas Vias de Acesso) }\end{array}$ & Não necessário & Pouco necessário & Muito necessário \\
\hline $\begin{array}{l}\text { Desenvolvimento da } \\
\text { região (Considerar } \\
\text { Fornecimento de } \\
\text { Energia Elétrica, } \\
\text { Saneamento e } \\
\text { Segurança para a } \\
\text { Região) }\end{array}$ & Melhora muito & Melhora pouco & Não melhora \\
\hline Satisfação do Usuário & $\begin{array}{c}1 \\
\text { Melhora muito }\end{array}$ & $\begin{array}{c}0 \\
\text { Melhora pouco }\end{array}$ & $\begin{array}{c}-1 \\
\text { Não melhora } \\
\end{array}$ \\
\hline Tempo de caminhada & $\begin{array}{c}1 \\
\text { Diminui muito } \\
\end{array}$ & $\begin{array}{c}0 \\
\text { Diminui pouco } \\
\end{array}$ & $\begin{array}{c}-1 \\
\text { Não diminui } \\
\end{array}$ \\
\hline Tempo de espera & $\begin{array}{c}1 \\
\text { Diminui muito } \\
\end{array}$ & $\begin{array}{c}0 \\
\text { Diminui pouco } \\
\end{array}$ & $\begin{array}{c}-1 \\
\text { Não diminui } \\
\end{array}$ \\
\hline
\end{tabular}

i) Segurança: adotar coeficiente 1, pois a implantação do corredor trará segurança à região. Caso contrário, adotar coeficiente -1 ;

ii) Urbanização do Igarapé: adotar coeficiente 1, pois a implantação do corredor deverá melhorar a urbanização do igarapé. Caso contrário adotar coeficiente -1;

iii) Fornecimento de Energia Elétrica: adotar coeficiente 1, pois com a modernização da via será fornecido luz elétrica pública para a população lindeira ao igarapé. Caso contrário considerar coeficiente -1 ; 
iv) Coleta de lixo diária: adotar coeficiente 1, pois para manter a limpeza da via e sua vida útil se faz necessário ter a coleta pública de lixo diariamente, além de manter uma boa aparência estética da mesma. Caso contrário considerar coeficiente -1;

v) Limpeza pública diária: adotar coeficiente 1, pois é necessária a limpeza diária e eficiente da via para manter a eficiência da mesma. Caso contrário considerar coeficiente -1 ;

vi) Fornecimento de água: adotar coeficiente 1, pois com a modernização da via será fornecido o abastecimento público de água para a população lindeira. Caso contrário considerar coeficiente -1 ;

vii)Coleta de esgoto: dotar coeficiente 1, pois a fim de evitar poluição do igarapé e proporcionar saneamento básico à população local será fornecida a coleta de esgoto. Caso contrário considerar coeficiente -1 ;

viii) Tempo de caminhada: adotar coeficiente 1, pois a média do tempo de caminhada da população tenderá a diminuir. Caso contrário considerar coeficiente -1;

ix) Tempo de espera: adotar coeficiente 1, pois com a criação do corredor e novas linhas de ônibus, o tempo de espera no ponto deve ser reduzido, aumentando a eficiência do sistema;

x) Satisfação do usuário: adotar coeficiente 1, pois com a melhoria do sistema aumenta a satisfação do usuário;

xi) Alterações viárias na redondeza: adotar coeficiente 1, pois serão realizada alterações nas ruas do entorno, a fim de facilitar o acesso ao corredor. Caso contrário considerar coeficiente -1 ;

xii) Congestionamentos: Adotar coeficiente 2, pois não haverá congestionamento na via, tanto para entrar quanto para sair, ou seja, um para cada caso. Caso contrário considerar coeficiente -1 para cada um dos casos; 
xiii) Movimentação de pessoal: adotar coeficiente 1, pois não será necessário mobilizar agentes de trânsito para regularizar o trânsito na via. Caso contrário considerar coeficiente -1 .

A Figura 9 apresenta as variáveis utilizadas na análise do grupo Mudanças na Região no sistema dinâmico.

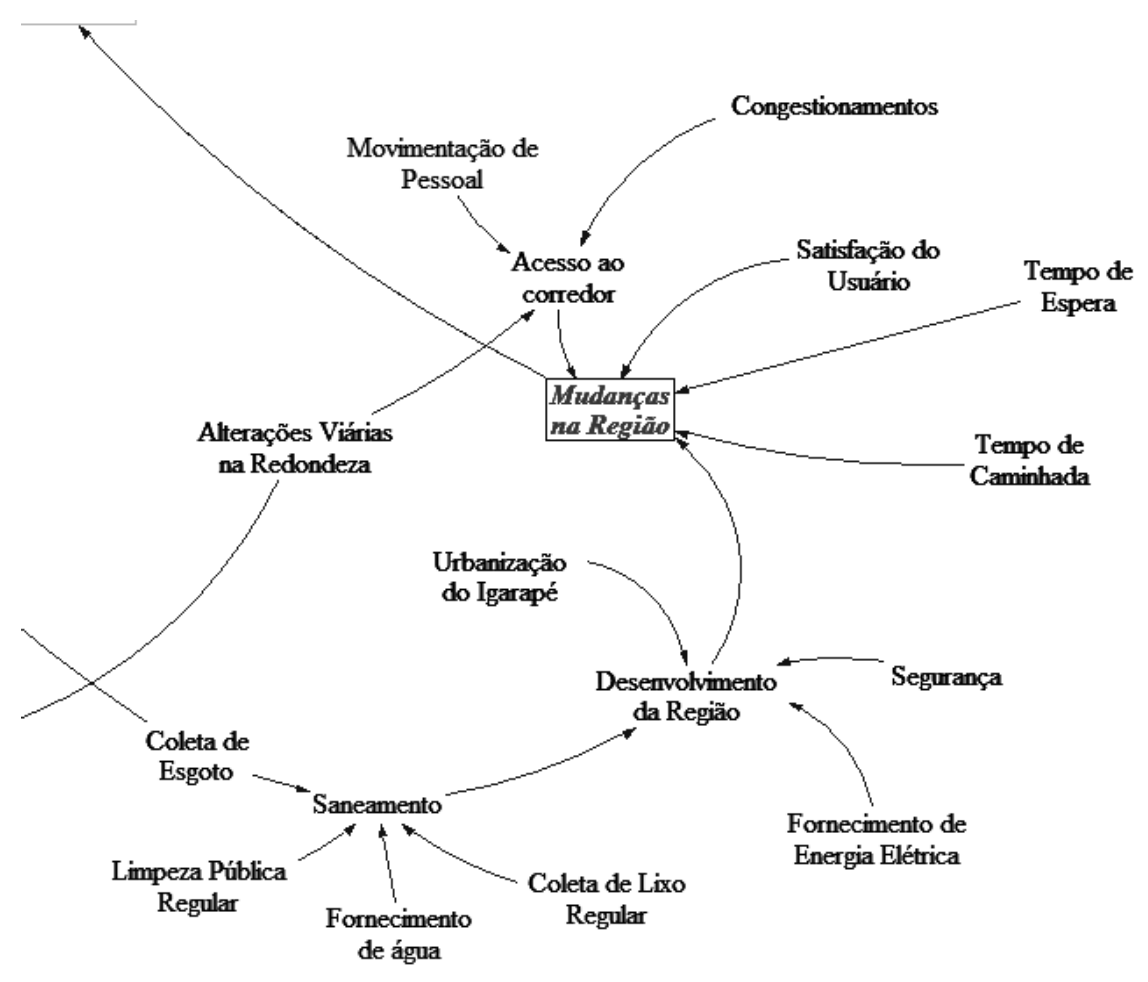

Figura 9 - Análise das mudanças na região ${ }^{17}$

Caso o resultado final do sistema seja um número maior ou igual a zero é viável implantar um novo corredor urbano nas condições propostas. Caso esse valor seja menor que zero, ou seja, negativo, se torna inviável essa implementação.

O detalhe da última área de análise da viabilidade da via no mapa do sistema dinâmico se encontra na Figura 10. Já o mapa completo a ser utilizado para análise de viabilidade de implantação do um corredor urbano ligando as Zonas Leste e Norte com o Centro da cidade é apresentado na Figura 11. 


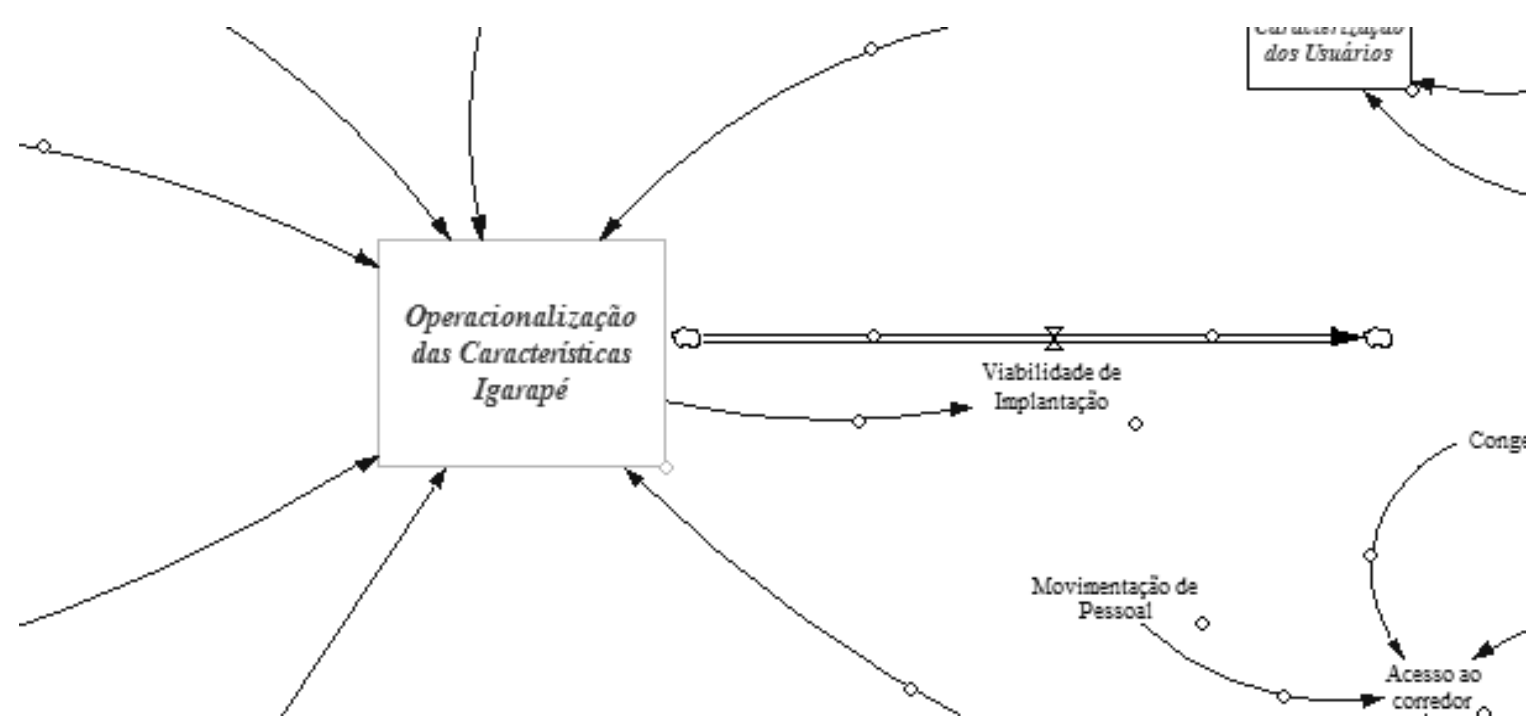

Figura 20 - Detalhe da área de análise final do sistema dinâmico ${ }^{18}$ 


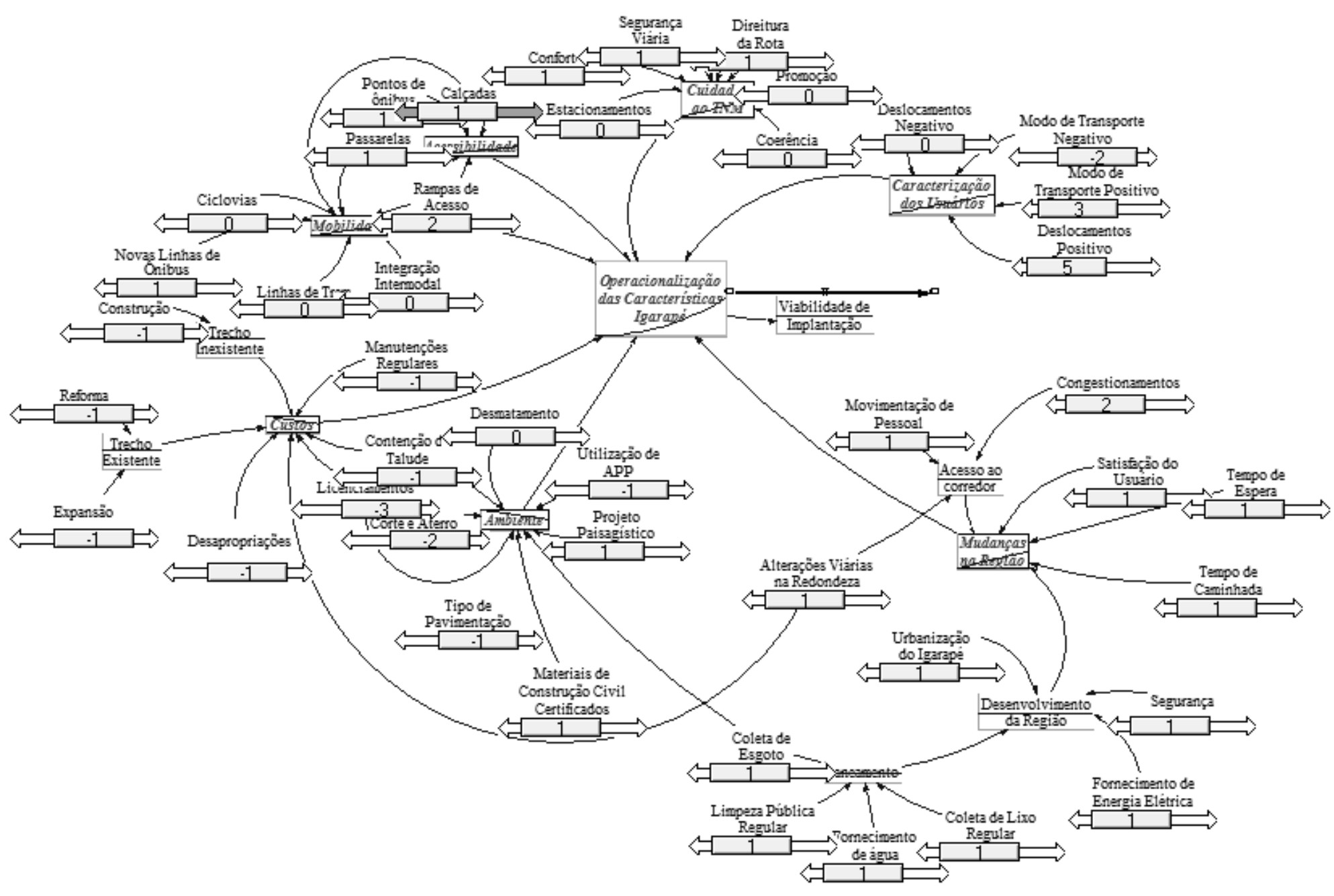

Figura 11 - Mapa de análise de viabilidade completo ${ }^{19}$ 
Para implementar o sistema foi utilizado o programa Vensim PLE, visto que possui versão gratuita e uma interface mais amigável e de fácil criação dos sistemas dinâmicos. Foram criadas fórmulas e funções com o objetivo de realizar as interações. Os fatores utilizados no sistema foram incrementados com fórmulas de acordo com a posição dos mesmos no mapa de análise e foram divididos em quatro fases. A primeira foi criada para alimentar os valores de cada subindicador, já a segunda tem o intuito de realizar o somatório dos elementos de cada indicador para poder dar prosseguimento à etapa seguinte, que consistia no somatório dos sete fatores principais. $\mathrm{Na}$ última fase foi aplicada uma função condicional para determinação da viabilidade ou não da construção de um novo corredor urbano.

A função condicional consiste em analisar o valor obtido no campo Operacionalização das Características Igarapé. Caso o valor deste tópico seja menor que 0, o programa retornará ao final o valor -1, que significa que é inviável a construção da nova via. E caso a soma dos valores de todos os tópicos seja maior ou igual a zero, o sistema dinâmico apresentará como resultado final o valor 1 (um), significando que é viável a construção do novo corredor.

Com isso pode-se dar procedimento à determinação da viabilidade de um corredor urbano por meio de um Sistema Dinâmico.

\section{Análise dinâmica de viabilidade de implantação de um novo corredor urbano}

A implantação de um corredor urbano tem o intuito de diminuir a quantidade de congestionamentos e, consequentemente, o tempo de viagem entre zonas da cidade. Visando esse objetivo, é realizada, a seguir, a análise de viabilidade para a implantação de uma via que liga as Zonas Leste e Norte ao Centro, através da Rua Canumã, no Igarapé da Lavanderia, localizado no bairro, por meio de sistema dinâmico de análise. 
O sistema utilizado integra a união de vários fatores delimitadores da atual condição e da situação futura da mobilidade, acessibilidade e condição de vida dos moradores da região do Igarapé da Lavanderia. São sete os tópicos principais de análise dessas condições, entre a acessibilidade, mobilidade, caracterização dos usuários, cuidados ao Transporte Não Motorizado (TNM), custos, ambiente e possíveis benefícios que essa implantação pode trazer à área estudada. Para a criação e utilização do sistema foi utilizado o software Vensim PLE para Windows versão 5.11A.

\subsection{Análise de viabilidade do projeto ideal}

O sistema foi alimentado com os coeficientes determinados na fase da metodologia. Após a alimentação dos dados, foi implementado o programa para seu efetivo funcionamento e, assim, efetuar a análise. Após o programa realizar todas as interações conclui-se, como esperado, que é viável a implantação de um corredor urbano.

A melhoria planejada para a região do Igarapé da Lavanderia deverá proporcionar a elevação dos níveis de atendimento dos sistemas de abastecimento de água, luz e esgoto, bem como a melhoria da oferta de transporte coletivo, através da inclusão de novas linhas, o que deverá reduzir o tempo de espera nos pontos de ônibus, além de menor tempo de caminhada, uma vez essas novas linhas trafegariam pelo novo corredor.

O novo corredor viário urbano serve como rota de fuga dos congestionamentos da cidade, principalmente para quem deseja se deslocar entre as zonas Norte, Leste e Centro da cidade.

A melhoria da acessibilidade e mobilidade da população deverá ocorrer com a implantação de calçadas, passarela e rampas de acesso. Esse mesmo fator influenciará diretamente as condições de acessibilidade, uma vez que deverá facilitará os deslocamentos a pé de forma mais rápida e menor esforço muscular.

Na Tabela 9 tem-se os resultados obtidos com a implementação dos fatores definidos anteriormente. Cada um dos sete itens estudados está representado pelas colunas de acordo com o passar do ano. Na última coluna, Viabilidade de Implantação, mostra o resultado final, apresentando o valor 1, ou seja, indica que é viável a implementação do corredor nas condições ideais. 
Tabela 9 - Resultados obtidos através do sistema dinâmico gerado no Vensim PLE coeficientes para o projeto ideal ${ }^{20}$

\begin{tabular}{|c|c|c|c|c|c|c|c|c|c|}
\hline 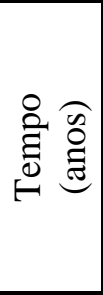 & 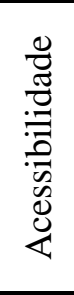 & 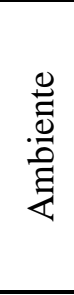 & 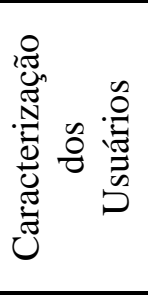 & 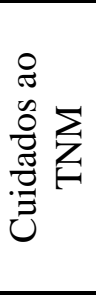 & 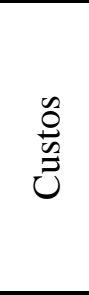 & $\begin{array}{l}\frac{\pi}{0} \\
\frac{\pi}{0} \\
: 0 \\
0 \\
\Sigma\end{array}$ & 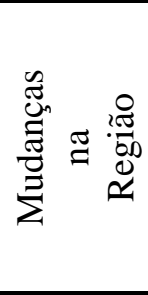 & 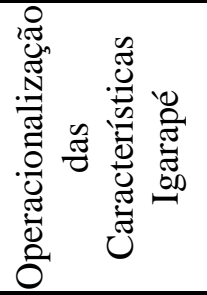 & 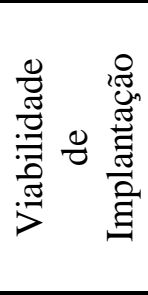 \\
\hline 0 & 5 & -4 & -4 & 3 & -9 & 5 & 10 & 6 & 1 \\
\hline 1 & 10 & -7 & 2 & 6 & -17 & 10 & 24 & 12 & 1 \\
\hline 2 & 15 & -10 & 8 & 9 & -25 & 15 & 38 & 40 & 1 \\
\hline 3 & 20 & -13 & 14 & 12 & -33 & 20 & 52 & 90 & 1 \\
\hline 4 & 25 & -16 & 20 & 15 & -41 & 25 & 66 & 162 & 1 \\
\hline 5 & 30 & -19 & 26 & 18 & -49 & 30 & 80 & 256 & 1 \\
\hline 6 & 35 & -22 & 32 & 21 & -57 & 35 & 94 & 372 & 1 \\
\hline 7 & 40 & -25 & 38 & 24 & -65 & 40 & 108 & 510 & 1 \\
\hline 8 & 45 & -28 & 44 & 27 & -73 & 45 & 122 & 670 & 1 \\
\hline 9 & 50 & -31 & 50 & 30 & -81 & 50 & 136 & 852 & 1 \\
\hline 10 & 55 & -34 & 56 & 33 & -89 & 55 & 150 & 1056 & 1 \\
\hline 11 & 60 & -37 & 62 & 36 & -97 & 60 & 164 & 1282 & 1 \\
\hline 12 & 65 & -40 & 68 & 39 & -105 & 65 & 178 & 1530 & 1 \\
\hline 13 & 70 & -43 & 74 & 42 & -113 & 70 & 192 & 1800 & 1 \\
\hline 14 & 75 & -46 & 80 & 45 & -121 & 75 & 206 & 2092 & 1 \\
\hline 15 & 80 & -49 & 86 & 48 & -129 & 80 & 220 & 2406 & 1 \\
\hline 16 & 85 & -52 & 92 & 51 & -137 & 85 & 234 & 2742 & 1 \\
\hline 17 & 90 & -55 & 98 & 54 & -145 & 90 & 248 & 3100 & 1 \\
\hline 18 & 95 & -58 & 104 & 57 & -153 & 95 & 262 & 3480 & 1 \\
\hline 19 & 100 & -61 & 110 & 60 & -161 & 100 & 276 & 3882 & 1 \\
\hline 20 & 105 & -64 & 116 & 63 & -169 & 105 & 290 & 4306 & 1 \\
\hline
\end{tabular}

A criação de projetos paisagísticos eficientes na região onde será implantada a via demonstra uma preocupação com o meio ambiente e o embelezamento da região, tornando-a mais aprazível e melhorando os níveis de qualidade de vida da população.

\subsection{Análise de viabilidade do projeto executável}

A situação adotada na seção anterior é o caso ideal para as condições de vias encontradas hoje na cidade de Manaus. Devido à baixa probabilidade de implantação do corredor urbano nessas condições será realizada, a seguir, uma análise da real situação a ser executada neste novo 
corredor urbano. Os valores dos coeficientes descritos na Tabela 10 abaixo estão de acordo com o que foi observado na implantação dos últimos projetos viários realizados em Manaus.

Tabela 10 - Coeficientes a serem adotados na simulação do que seria executado caso seguido as características atuais nos projetos viários da cidade ${ }^{21}$

\begin{tabular}{|c|c|c|c|}
\hline Item & Subitem & Especificação & Coeficiente \\
\hline \multirow{4}{*}{ Acessibilidade } & Calçadas & - & 1 \\
\hline & Passarelas & - & 0 \\
\hline & Pontos de Ônibus & - & 1 \\
\hline & Rampas de Acesso & - & -2 \\
\hline \multirow{7}{*}{ Mobilidade } & Calçadas & - & Idem \\
\hline & Ciclovias & - & 0 \\
\hline & Integração Intermodal & - & 0 \\
\hline & Linhas de trem & - & 0 \\
\hline & $\begin{array}{l}\text { Novas Linhas de } \\
\text { Ônibus }\end{array}$ & - & 1 \\
\hline & Passarelas & - & Idem \\
\hline & Rampas de acesso & - & Idem \\
\hline \multirow{6}{*}{ Cuidados ao TNM } & Coerência & - & 0 \\
\hline & Conforto & - & 0 \\
\hline & Direitura da Rota & - & 0 \\
\hline & Estacionamentos & - & 0 \\
\hline & Promoção & - & 0 \\
\hline & Segurança Viária & - & 0 \\
\hline \multirow{8}{*}{ Custos } & $\begin{array}{l}\text { Alterações Viárias na } \\
\text { Redondeza }\end{array}$ & - & Idem \\
\hline & Contenção de Talude & - & -1 \\
\hline & Desapropriações & - & -1 \\
\hline & Licenciamentos & - & -3 \\
\hline & Manutenções Regulares & - & -2 \\
\hline & \multirow{2}{*}{ Trecho existente } & Expansão & -1 \\
\hline & & Reforma & -1 \\
\hline & Trecho Inexistente & Construção & -1 \\
\hline \multirow{10}{*}{ Ambiente } & Coleta de Esgoto & \multicolumn{2}{|c|}{$\begin{array}{l}- \\
\text { Idem }\end{array}$} \\
\hline & Contenção de talude & - & - Idem \\
\hline & Corte e Aterro & - & -2 \\
\hline & Desmatamento & - & 0 \\
\hline & Licenciamentos & - & Idem \\
\hline & $\begin{array}{c}\text { Materiais de } \\
\text { Construção Civil } \\
\text { Certificados }\end{array}$ & - & 1 \\
\hline & Projeto Paisagístico & - & 0 \\
\hline & Tipo de Pavimentação & - & -1 \\
\hline & Urbanização do Igarapé & - & Idem \\
\hline & Utilização de APP & - & -1 \\
\hline
\end{tabular}




\begin{tabular}{|c|c|c|c|}
\hline \multicolumn{4}{|c|}{ Continuação tabela 10} \\
\hline \multirow{4}{*}{$\begin{array}{c}\text { Caracterização dos } \\
\text { usuários }\end{array}$} & $\begin{array}{l}\text { Deslocamentos } \\
\text { Positivos }\end{array}$ & - & 5 \\
\hline & $\begin{array}{c}\text { Deslocamentos } \\
\text { Negativos }\end{array}$ & - & 0 \\
\hline & $\begin{array}{l}\text { Meio de Transporte } \\
\text { positivo }\end{array}$ & - & 3 \\
\hline & $\begin{array}{c}\text { Meio de Transporte } \\
\text { negativo }\end{array}$ & - & 2 \\
\hline \multirow{10}{*}{ Mudanças na Região } & \multirow{3}{*}{ Acesso ao Corredor } & Alterações Viárias & -1 \\
\hline & & Congestionamentos & -2 \\
\hline & & $\begin{array}{c}\text { Movimentação de } \\
\text { pessoal }\end{array}$ & -1 \\
\hline & \multirow{4}{*}{$\begin{array}{l}\text { Desenvolvimento da } \\
\text { região }\end{array}$} & $\begin{array}{c}\text { Fornecimento de } \\
\text { energia elétrica }\end{array}$ & 0 \\
\hline & & Saneamento" & 2 \\
\hline & & Segurança & 1 \\
\hline & & $\begin{array}{l}\text { Urbanização do } \\
\text { Igarapé }\end{array}$ & 1 \\
\hline & Satisfação do Usuário & - & 0 \\
\hline & Tempo de caminhada & - & 1 \\
\hline & Tempo de espera & - & 1 \\
\hline
\end{tabular}

Para implementar o sistema, foi aproveitado o mesmo mapa utilizado para a análise nas condições do projeto ideal. O incremento foi a implementação dos índices indicados na tabela acima, os quais são específicos dos projetos já existentes em Manaus, simulando suas principais características.

Ao aplicar as funções de simulação do mapa para obtenção dos dados relativos à viabilidade ou não do projeto, chegou-se ao valor de -1 como resposta. Portanto, nas condições em que são pensados, planejados e executados os projetos viários hoje em Manaus, não é viável a implementação de um corredor urbano que ligue as zonas Norte e Leste ao centro de Manaus.

Na Tabela 11, a coluna Viabilidade de Implantação, que mostra o resultado final da implementação do sistema para uma projeção dos próximos 20 anos, apresenta o valor -1, mostrando que com as condições identificadas e consideradas na elaboração e execução de projetos em Manaus não torna viável a execução de novos corredores urbanos na cidade.

* Saneamento se divide ainda em Coleta de Lixo Regular (1), Limpeza Pública Regular (0), Fornecimento de JÁgua ( $(0)$ Coleta de Esgoto (1) sendo seu valor a somatória desses itenens. 
Tabela 11 - Resultados obtidos através do sistema dinâmico gerado no Vensim PLE coeficientes para o projeto a ser executado. ${ }^{22}$

\begin{tabular}{|c|c|c|c|c|c|c|c|c|c|}
\hline 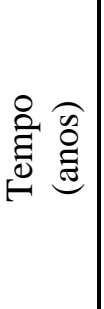 & 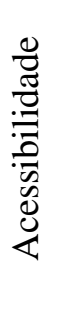 & 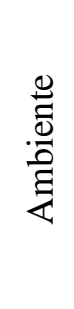 & 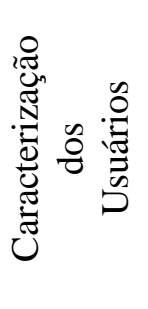 & 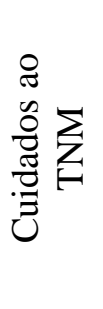 & 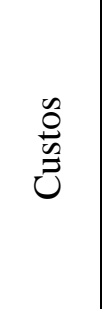 & $\begin{array}{l}\frac{0}{0} \\
\frac{\pi}{0} \\
: 07 \\
0 \\
0\end{array}$ & 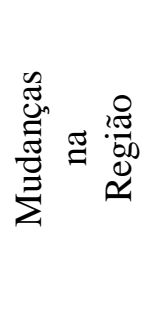 & 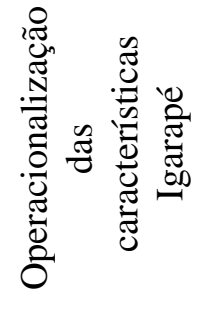 & 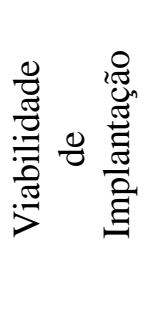 \\
\hline 0 & 0 & -4 & -4 & 0 & -10 & 0 & 6 & -12 & -1 \\
\hline 1 & 0 & -7 & 2 & 0 & -21 & 0 & 8 & -24 & -1 \\
\hline 2 & 0 & -10 & 8 & 0 & -32 & 0 & 10 & -42 & -1 \\
\hline 3 & 0 & -13 & 14 & 0 & -43 & 0 & 12 & -66 & -1 \\
\hline 4 & 0 & -16 & 20 & 0 & -54 & 0 & 14 & -96 & -1 \\
\hline 5 & 0 & -19 & 26 & 0 & -65 & 0 & 16 & -132 & -1 \\
\hline 6 & 0 & -22 & 32 & 0 & -76 & 0 & 18 & -174 & -1 \\
\hline 7 & 0 & -25 & 38 & 0 & -87 & 0 & 20 & -222 & -1 \\
\hline 8 & 0 & -28 & 44 & 0 & -98 & 0 & 22 & -276 & -1 \\
\hline 9 & 0 & -31 & 50 & 0 & -109 & 0 & 24 & -336 & -1 \\
\hline 10 & 0 & -34 & 56 & 0 & -120 & 0 & 26 & -402 & -1 \\
\hline 11 & 0 & -37 & 62 & 0 & -131 & 0 & 28 & -474 & -1 \\
\hline 12 & 0 & -40 & 68 & 0 & -142 & 0 & 30 & -552 & -1 \\
\hline 13 & 0 & -43 & 74 & 0 & -153 & 0 & 32 & -636 & -1 \\
\hline 14 & 0 & -46 & 80 & 0 & -164 & 0 & 34 & -726 & -1 \\
\hline 15 & 0 & -49 & 86 & 0 & -175 & 0 & 36 & -822 & -1 \\
\hline 16 & 0 & -52 & 92 & 0 & -186 & 0 & 38 & -924 & -1 \\
\hline 17 & 0 & -55 & 98 & 0 & -197 & 0 & 40 & -1032 & -1 \\
\hline 18 & 0 & -58 & 104 & 0 & -208 & 0 & 42 & -1146 & -1 \\
\hline 19 & 0 & -61 & 110 & 0 & -219 & 0 & 44 & -1266 & -1 \\
\hline 20 & 0 & -64 & 116 & 0 & -230 & 0 & 46 & -1392 & -1 \\
\hline
\end{tabular}

Os dois principais fatores a influenciarem a inviabilidade de implantação do novo corredor foram o fato de a acessibilidade e mobilidade não serem atendidas de forma eficiente, uma vez que não serão construídas passarelas para travessia de pedestres ou rampas de acesso para portadores de necessidades especiais. Apesar da previsão de construção de calçadas, as mesmas não atendem as exigências especificadas pelo ANTP (2007), no que diz respeito ao conforto, segurança e direitura. Isto se deve ao fato das calçadas não possuírem arborização, o que poderia amenizar a sensação térmica, dadas a alta temperatura local.

\footnotetext{
${ }^{21}$ Fonte: Autores.
} 
Além do mais, muitas das calçadas implantadas em Manaus em projetos recentes possuem muitas interferências, entre as quais o excesso de placas, bancos e pontos de telefone, impossibilitando assim um caminhar contínuo e sem desvios do pedestre. Outro ponto a ressaltar diz respeito à falhas na oferta de grau de segurança adequado quanto a situações imprevistas, como acidentes com os veículos da via e possível avanço ao nível da calçada.

Outros fatores que influenciaram este resultado negativo são: alto número de desapropriações para implantação do projeto, grande número de adequações a novas realidades nas vias e grande quantidade de manutenções preventivas.

O intuito desse projeto é oferecer à população uma nova via para interligar as zonas mais povoadas com a região mais acessada da cidade de Manaus. Porém, devido a falta de projetos de vias de acesso ao corredor, o fluxo de veículos no novo corredor urbano, pressupõe-se, seria livre e ininterrupto, o que poderia induzir os motoristas a empreenderem maiores velocidades a seus veículos, aumentando assim os riscos de acidentes de trânsito. Além disso, esse volume de veículos deverá se acumular nas saídas do corredor, o que poderá gerar novos congestionamentos.

É certo que medidas de engenharia de tráfego teriam que ser realizadas para mitigar esses impactos, mas estas não estão previstas no projeto do novo corredor viário, deixando-se claro, entretanto, que tais situações foram idealizadas usando-se como parâmetro as últimas obras viárias realizadas em Manaus, como a do Complexo Viário Antônio Simões, do Complexo Viário Gilberto Mestrinho e da Avenida Governador José Lindoso.

Nas proximidades do novo corredor urbano serão realizadas melhorias para a população, tais como fornecimento de energia elétrica, saneamento básico e segurança. Entretanto, as residência mais afastadas do corredor podem não ser beneficiadas com tais ações, o que poderia inferir diferenças sociais numa mesma região, ressaltando aqui, mais uma vez, que situações foram idealizadas usando-se como parâmetro obras já realizada na cidade de Manaus. 


\section{Conclusão}

A cidade de Manaus continua crescendo, principalmente nas zonas Norte e Leste. Mesmo assim, a quantidade de serviços existentes no centro é muito grande, forçando grande parte da população a se deslocar para essa região. Diante disso, este trabalho teve o intuito de determinar a viabilidade de implantação de um novo corredor viário na região do Igarapé da Lavanderia, no bairro de Petrópolis, em Manaus, a partir da implementação de um sistema dinâmico, a fim de melhorar a mobilidade da região e da cidade como um todo. É relevante destacar que o principal objetivo desse corredor é ligar as zonas Norte e Leste de Manaus ao Centro da cidade.

O mapa utilizado para a análise de viabilidade de implantação de um novo corredor urbano na região do Igarapé da Lavanderia, através da Dinâmica de Sistemas, foi idealizado com uma grande quantidade de variáveis que envolvem a construção de uma nova via, para que a análise seja efetuada com características mais próximas às encontradas no desenvolvimento desses projetos.

Para tal, foram definidos previamente sete indicadores, entre eles tem-se custo de construção, acessibilidade, mobilidade e outros. Para cada um desses itens foram definidos subindicadores aonde foram acrescidos coeficientes que puderam gerar a análise final de viabilidade de implantação do corredor. Cada coeficiente foi determinado a partir do que é encontrado na literatura vigente relacionada a criação de corredores urbanos, com suas características adaptadas a Manaus.

Foi escolhida a análise através dos Sistemas Dinâmicos, pois com mesmo se pode fazer a interligação entre os indicadores e subindicadores previamente determinados. Com essa ligação se pode ter uma melhor simulação da realidade encontrada no local e, consequentemente, um resultado mais condizente com a realidade do local conforme pode ser observado abaixo.

Com isso, observou-se que o método escolhido atendeu de forma satisfatória o objetivo a ele proposto de forma simples e eficiente. 
A referida pesquisa simulou dois casos, por meio da metodologia proposta de sistemas dinâmicos. O primeiro seria a implantação do corredor urbano nas condições ideais encontradas na literatura e órgãos financiadores, adaptado as características de Manaus, utilizado para validar o sistema criado, e no outro se utilizou as características de projetos encontradas em Manaus, tendo como base as três últimas obras da cidade inauguradas nos últimos cinco anos e próximas à região do igarapé da Lavanderia, Avenida Governador José Lindoso, Complexo Viário Gilberto Mestrinho, na Avenida Ephigiênio Salles, e Complexo Viário Antônio Simões.

Foram analisados ao todo sete itens principais, divididos em fatores que os influenciavam diretamente. Esses itens são: Acessibilidade, Mobilidade, Cuidados ao Transporte Não Motorizado, Caracterização dos Usuários, Ambientes, Custos e Mudanças na Região.

No primeiro caso, a via foi considerada viável, uma vez que se consideraram todas as condições ideais de implantação. Nesse caso, a acessibilidade da população teve seus principais itens atendidos (calçadas, passarelas, pontos de ônibus e rampas de acesso). Apesar de a cidade usar somente o transporte rodoviário e não motorizado como formas de deslocamento, o projeto não fica comprometido pelo fato de se ter uma maior satisfação e uso do novo sistema por parte da população. Foram tomados todos os cuidados necessários para a total eficiência do transporte não motorizado no local, principalmente o transporte a pé, além da adequada e necessária urbanização à região.

Os custos elevados do projeto são minimizados com o passar dos anos, uma vez que o corredor viário se paga com o uso constante da população. Para minimizar esse fator, devemse realizar todas as manutenções programadas, sendo que com isso não existiria gastos elevados com manutenções que não estejam previstas.

Já no segundo caso, chegou-se a conclusão de que é inviável a construção deste novo corredor urbano na região do Igarapé da Lavanderia. Isso se dá pelo fato dos projetos executados em Manaus não atenderem às condições mínimas de acessibilidade e mobilidade. Por não existirem planos de adequação de vias de acesso ao novo corredor viário, há a possibilidade dos motoristas inferirem maiores velocidades, o que, nos pontos de saída ou possíveis de interseção que possam surgir, poderá ocasionar congestionamentos. 
Aos custos de construção e infraestrutura são acrescidos os custos com manutenção, seja ela preventiva periódica ou corretiva rotineira, conforme indica Pedrozo (2001). Como, após a entrega da via, os serviços de manutenção não são praticados com a devida atenção e regularidade, a vida útil da via é reduzida, aumentando, inclusive, os riscos de acidentes. Além do mais, os custos com sua recuperação deverão requerer maiores gastos.

A criação de novas vias em Manaus não costuma oferecer outras melhorias que não sejam simplesmente mais uma opção viária ao trânsito caótico da cidade. Fatores importantes para a melhoria da qualidade de vida da população, como calçadas amplas, arborização, rampas de acesso, passarelas, ciclovias, faixas exclusivas ou segregadas para o transporte coletivo não são considerados. Um exemplo recente que pode ser citado é o da Avenida Governador José Lindoso, que não possui ciclovias, suas calçadas não atendem aos requisitos mínimos de mobilidade, como calçadas largas, direitura e conforto, não possuem muitas rampas de acesso a portadores de necessidades especiais e passarelas para a travessia da via de forma rápida segura e eficiente.

Constata-se, então, que não é viável construir um novo corredor viário no Igarapé da Lavanderia, entre as Avenidas André Araújo e Codajás, no bairro Petrópolis, na cidade de Manaus. Isso porque não são considerados no projeto e execução de vias, assim como nas obras de arte em Manaus, fatores importantes como maior acessibilidade e mobilidade à população, alem de outros indicados pela ANTP, através da série Cadernos Técnicos, e Banco Mundial, no produto técnico intitulado Cidades em Movimento.

Caso não sejam revistos os conceitos e a importância de acessibilidade e mobilidade por parte dos gestores de trânsito e transporte, não será tecnicamente viável a implantação deste projeto ou de qualquer outro projeto viário na cidade de Manaus. 


\section{Referências}

Associação Nacional de Transportes Públicos - ANTP (2007a) Cadernos Técnicos. Integração nos transportes públicos. São Paulo: [s.ed].

Associação Nacional de Transportes Públicos - ANTP (2007b) Cadernos Técnicos. Integração nos transportes públicos. São Paulo: [s.ed.]

Associação Nacional de Transportes Públicos - ANTP (1999) Integração nos Transportes Públicos. Uma análise dos sistemas implantados. São Paulo: [s.ed.].

Banco Mundial (2003). Cidades em Movimento. Estratégias de Transporte Urbano do Banco Mundial. São Paulo: Sumatra Editorial.

Carvalho, E. B. e Silva, P. C. M. (s.d.) Indicadores de acessibilidade no sistema de transporte coletivo. Proposta de classificação em níveis de serviço. Brasília: [s.ed.].

Centro Interdisciplinar de Estudos em Transporte - CEFTRU (2006) Projeto de reestruturação do transporte coletivo urbano de Manaus - RTC/MAO. Documento de Trabalho - CEFTRU (não publicado).

Cunha, M. J. T., Maia, M. L. A. e Lima Neto, O. C. C (2004) Acessibilidade, Transporte e Reestruturação Urbana. Congresso de Pesquisa e Ensino em Transportes, Santa Catarina.

Fernandes Junior, J. L. Alinhamento Horizontal e Vertical. In: 〈http://www.dec.uem.br/ >

Instituto Brasileiro de Geografia e Estatística - IBGE (2010) Censo 2010. Documento de Trabalho $I B G E$.

Raia Junior, A. A. (2000) Acessibilidade e mobilidade na estimativa de um índice de potencial de viagens utilizando redes neurais artificiais e sistemas de informações geográficas. Tese (Doutorado em Engenharia de Transportes), Universidade de São Paulo, São Paulo.

Santos, A. M. S. (2006) A Aplicação de um modelo de simulação para o gerenciamento de projetos: Um estudo de caso utilizando a dinâmica de sistemas. Dissertação (Mestrado em Engenharia de Transportes), Universidade de São Paulo, São Paulo.

Secretaria Municipal de Meio Ambiente e Sustentabilidade - SEMMAS (2001) Código Ambiental de Manaus. Documento de Trabalho - SEMMAS.

Ventana Systems, Inc (2004) Dinâmica de Sistemas. Documento de Trabalho - Ventana Systems. 